\title{
Dissociable Effects of Antagonism of NMDA and AMPA/KA Receptors in the Nucleus Accumbens Core and Shell on Cocaine-seeking Behavior
}

\author{
Patricia Di Ciano, Ph.D., and Barry J. Everitt, Ph.D.
}

The purpose of the present experiment was to investigate the involvement of $N M D A$ and $A M P A / K A$ receptors in the nucleus accumbens core and shell in the control over cocaine-seeking behavior by drug-associated cues. Rats were trained under a second-order schedule of reinforcement for cocaine with five infusions of cocaine being available in each daily session. The NMDA receptor antagonist AP-5 and the AMPA/KA receptor antagonist LY293558 were infused directly into the core or shell. LY293558 infused into the core produced a dose-dependent decrease in responding during both the first, cocaine-unaffected interval and also after cocaine had been self-administered in subsequent intervals. By contrast, AP-5 infused into the core had no effect on responding. Infusion of AP-5 into the shell had the limited effect of decreasing responding during the second interval only. There were no effects of LY293558 infused into the shell. These results indicate that NMDA and AMPA receptor-mediated glutamate transmission in the core and shell are dissociably involved in cocaine-seeking behavior controlled in part by drug-associated cues. [Neuropsychopharmacology 25:341-360, 2001] (C) 2001 American College of Neuropsychopharmacology. Published by Elsevier Science Inc.
KEY WORDS: Self-administration; Drug addiction: Drug-seeking; Glutamate receptors; Second-order schedule

Cues associated with drugs abused by humans, especially stimulants such as cocaine, acquire powerful motivational effects which can induce strong cravings for the drug and are considered to be major factors in precipitating drug-seeking behavior and relapse to a drug-

From the Department of Experimental Psychology, University of Cambridge, Downing Street, Cambridge, CB2 3EB, UK.

Address correspondence to: Dr. P. Di Ciano, University of Cambridge, Dept. of Experimental Psychology, Downing Street, Cambridge CB2 3EB, Tel.: 44 1223-333583, Fax: 44 1223-333564, Email: pd241@cus.cam.ac.uk

Received October 5, 2000; revised January 19, 2001; accepted February 5, 2001.

Online publication: 2/12/01 at www.acnp.org.citations/Npp 2090178. taking habit (Gawin and Kleber 1986; O'Brien et al. 1998). The strength of this conditioned influence on addictive behavior in humans may lie in the fact that, having precipitated relapse to drug-seeking, the renewed self-administration of drugs like cocaine both strengthens the conditioned properties of the drug-associated cues and also amplifies their effects on behavior (Everitt et al. 1999).

The NAcc is widely accepted to be a primary site mediating the reinforcing effects of cocaine and other drugs (Koob 1999; Martin-Iversen et al. 1986; Roberts and Koob 1982; Roberts et al. 1980; Wise 1996). Moreover, Robinson and Berridge (1993) have suggested that sensitization of NAcc dopamine (DA) transmission by repeated exposure to stimulants results in the enhanced impact of drug-associated stimuli and thereby drug wanting and craving (Robinson and Berridge 1993). The observation that non-contingent presentations of drug- 
paired cues can increase DA efflux in the NAcc (Di Ciano et al. 1998a, 1998b) and preferentially in the core subregion (Ito et al. 2000), suggests that subregions of the NAcc may mediate dissociable mechanisms underlying conditioned influences on drug-seeking behavior. Indeed, this suggestion is supported by the finding that selective lesions of the NAcc core disrupted discriminated approach to a stimulus paired with primary reward in a Pavlovian autoshaping procedure (Parkinson et al. 1999, 2000b), while lesions of the shell had no such effect, but attenuated the locomotor stimulant and conditioned reinforcement-potentiating effects of amphetamine (Parkinson et al. 1999).

The associative and other processes subserved by the NAcc core and shell presumably depend upon their glutamatergic afferents originating in limbic cortical sites, especially the basolateral amygdala, anterior cingulate and prelimbic cortices and hippocampal formation (Groenewegen et al. 1991, 1999). These cortical afferents show distinctive patterns of termination in the core (e.g. anterior cingulate cortex) and shell (e.g. ventral subiculum) (Groenewegen et al. 1987, 1996; Heimer et al. 1991; Kelley et al. 1982) and have been shown to interact with DA in the NAcc in electrophysiological, neurochemical and behavioral studies (Blaha et al. 1997; Floresco et al. 1998; Kelley et al. 1982; Walaas and Fonnum 1980). Indeed, in the context of addictive behavior, infusion of the AMPA/KA receptor antagonist CNQX, but not the NMDA receptor antagonist AP-5, into the NAcc reduced the reinstatement of cocaine-seeking induced by a systemic cocaine injection, while AMPA receptor stimulation itself reinstated cocaine-seeking behavior (Cornish et al. 1999).

More detailed investigation of the effects of glutamatergic receptor antagonism in the core and shell has indicated dissociable influences on behavior of glutamate receptors in these two subregions of the NAcc. Thus, infusion of the NMDA receptor antagonist AP-5 into the NAcc core dose-dependently reduced locomotion, while injections into the shell either had no effect on, or increased, exploratory behavior (Maldonaldo-Irizarry and Kelley 1994). Further, NMDA receptor antagonists infused into the NAcc core blocked the acquisition of responsereinforcement learning, while infusion into the shell produced much smaller impairments (Kelley et al. 1997). In a recent study that compared reaction times of responses for reward in the presence of stimuli predictive of different reward magnitudes, reaction times were shorter in the presence of stimuli predictive of high, than in the presence of stimuli predictive of lower, reward. Infusion of AP-5 into the NAcc, in the region of the core, impaired the shortening of reaction-times normally seen in rats expecting high reward (Hauber et al. 2000). Together, these studies suggest a critical role for the core and its afferents in appetitive behavior under the control of reward-associated stimuli.

The purpose of the present experiment was to test the hypothesis that cocaine-seeking behavior under the control of drug-associated cues depends upon glutamatergic afferents to the NAcc core and shell that carry this associative information from limbic cortical sites, thereby gaining access to dopamine-modulated response mechanisms (Everitt et al. 1999). We have therefore investigated the effects of infusing the NMDA receptor antagonist, AP-5, and the novel AMPA/KA receptor antagonist, LY293558, directly into the NAcc core and shell on responding for cocaine under a second-order schedule of reinforcement. Under the second-order schedule used in the present study, cocaine was available following completion of a fixed ratio (FR) of 10 responses after an overall fixed interval (FI) 15 minutes had timed out; during the (FI) 15 minutes, each FR10 responses was reinforced, and thereby maintained, by presentation of a cocainepaired conditioned stimulus (Arroyo et al. 1998). Responding under the two schedule components shows distinct and dissociable patterns (Goldberg et al. 1975), and therefore allows for measurement of both drugfree, cocaine-seeking behavior during the first interval of a daily session, and also drug-seeking that is influenced by the reinforcing and other, e.g. response-rate altering, effects of self-administered cocaine during the second and subsequent intervals of a session (Arroyo et al. 1998; Everitt and Robbins 2000). The AMPA/KA receptor antagonist used in this study, LY293558, is approximately 10 fold selective for AMPA over NMDA receptors (Schoepp et al. 1995) and also has GluR5 kainate receptor antagonist properties (Bleakman et al. 1996). It is freely water soluble, and therefore offers distinct advantages over those AMPA receptor antagonists requiring solvents such as DMSO (e.g. DNQX and CNQX ) to solubilize them for delivery into the brain.

\section{METHODS}

\section{Animals}

Thirty-four male Listar Hooded rats weighing 280-300 grams at the time of surgery (Charles River) were individually housed under a reversed 12 hour light-dark cycle (lights on at 8 P.M.). On the day prior to the start of testing, rats were placed on a restricted diet of 20 grams of Purina lab chow/day, sufficient to maintain body weight and growth throughout the experiment. Water was available freely and food was given within six hours after daily testing. Experiments were carried out between 9 A.M. and 8 P.M., six or seven days a week. Experiments were conducted in accordance with the United Kingdom 1986 Animals (Scientific Procedures) Act (Project License PPL 80/1324).

\section{Apparatus}

Rats were tested in operant chambers (Med Associates; $29.5 \mathrm{~cm} \times 32.5 \mathrm{~cm} \times 23.5 \mathrm{~cm}$ ). Three sides were con- 
structed from Perspex and the fourth was made of stainless steel, on which two 4-cm wide retractable levers were secured. The two levers were $12 \mathrm{~cm}$ apart, and $8 \mathrm{~cm}$ from the grid floor. Above each lever was a cue light (2.5-W, 24$\mathrm{V})$, and a red house light $(2.5-\mathrm{W}, 24-\mathrm{V})$ was located on the opposite wall. The floor of the chamber was lined with absorbent paper and covered with a metal grid. The testing chamber was placed within a sound- and light-attenuating box, equipped with a ventilation fan that also screened external noise. Silastic tubing shielded with a metal spring extended from each animal's i.v. catheter to a liquid swivel (Stoelting, Wood Dale, Ill., USA) mounted on an arm fixed outside of the operant chamber. Tygon tubing extended from the swivel to a Razel infusion pump (Semat Technical Ltd., Herts, UK) located adjacent to the external chamber. The operant chamber was interfaced to software running on an Acorn Archimedes microcomputer (Acorn Computers Ltd., Cambridge, UK), programmed in the BASIC control language, Arachnid (Fray et al. 1980). The shell experiment was controlled by software written by RNC in C ++ using the Whisker control system (Cardinal 2000).

\section{Surgery}

Rats were anesthetized with ketamine hydrochloride $(100 \mathrm{mg} / \mathrm{kg}$ i.p.; Ketaset) and xylazine $(9 \mathrm{mg} / \mathrm{kg}$ i.p.; Rompun) and supplemented with ketamine as needed ( $\sim 20 \mathrm{mg}$ ). All rats were implanted with a single catheter in the right jugular aimed at the left vena cava. Catheters were made in-house from 22-g cannulae with elongated ends (Plastic Products Inc). Silastic tubing (0.012 I.D.) was secured to the bottom end of the cannula, and the top was fixed to nylon mesh with dental acrylic and silicone. The mesh end of the catheter was sutured sub-cutaneously (s.c.) on the dorsum. All surgical instruments were thoroughly sterilized prior to surgery. To prevent infection, rats were treated post-surgically with $10 \mathrm{mg} / \mathrm{kg}$ Baytril (Bayer) s.c. for eight days. See Caine for details (Caine et al. 1992).

Immediately following catheter implantation, rats were positioned in a stereotaxic frame for insertion of guide cannulae. Guide cannulae consisted of 24-g thinwalled stainless steel tubing (Cooper's Needleworks, $\mathrm{UK}$ ) and lowered to $2.5 \mathrm{~mm}$ above the target site (core: +1.2 AP; $\pm 1.8 \mathrm{ML}$; -4.7 DV; shell: +1.0 AP; $\pm 1.0 \mathrm{ML}$; 5.3 DV; incisor bar $-3.3 \mathrm{~mm}$ (Paxinos and Watson 1986)). Cannulae were secured with stainless steel screws and dental acrylic; 29-g wire stylets (Cooper's Needleworks) were inserted into the length of the guide cannulae to maintain patency.

\section{Procedure}

Acquisition of cocaine self-administration. Daily experimental testing began seven to ten days after surgical procedures. On each self-administration day, rats were connected to the i.v. line in the testing box and the experimental session was begun when the experimenter depressed one of the two levers three times, thereby illuminating the house light and designating that lever as active. Active and inactive levers were counterbalanced between left and right sides for individual animals. "Priming" injections of cocaine were never given. During initial training, rats acquired a lever press response for cocaine $(0.75$ $\mathrm{mg} / \mathrm{kg} / \mathrm{inf} / 0.1 \mathrm{~mL} / 5 \mathrm{sec}$ ) under a fixed-ratio (FR-1, Time-Out 20 s) schedule of reinforcement. On this schedule each bar press resulted in illumination of the stimulus light above the lever, retraction of both levers, and extinction of the house light for $20 \mathrm{~s}$. During the 20-s "time out", bar presses had no consequence. Following this 20-s interval, the house light was again illuminated, the stimulus light was extinguished, and the two levers were again inserted into the testing box. Presses on the inactive lever had no programmed consequences, but were recorded to assess general levels of activity. Following three days of stable responding on this schedule, a second-order schedule was gradually introduced.

Acquisition of responding under a second-order schedule. A second-order schedule of the type $\operatorname{FRx}(\mathrm{FRy}: \mathrm{S})$ was introduced, such that $x$ number of unit schedule requirements resulted in a cocaine infusion, and y number of lever presses resulted in illumination of the stimulus light for $1 \mathrm{~s}$ within the unit schedule. Therefore, under a second-order schedule, rats were presented with two stimuli: 1) a 1-s illumination of the stimulus light after y responses, and 2) a 20-s illumination of the stimulus light during cocaine infusion. The schedule requirements were gradually increased, beginning with a value of y set at 1 and a value of $x$ of 5; each lever press resulted in 1-s CS presentations, and following five such CS presentations, rats received a cocaine infusion and associated 20-s presentation of this stimulus light. Subsequently, the response requirements increased to FR10(FR1:S), FR10(FR2:S), FR10(FR4:S), FR10(FR7:S) and FR10(FR10:S). Following stable responding under the final schedule, a fixed interval FI 15-min(FR10:S) schedule was introduced, and rats were allowed to stabilize and establish individual patterns of responding under this schedule. Under this schedule, cocaine was available following completion of a fixed ratio (FR) of 10 responses after an overall fixed interval (FI) 15 minutes had timed out; during the (FI) 15 minutes, each FR10 response was reinforced by presentation of the drugpaired CS. Animals were permitted five infusions of cocaine per day under this schedule.

\section{Microinfusions}

Following the acquisition of stable responding under a FI15(FR10:S) schedule of reinforcement for two days ( \pm $20 \%$ variation in response rate during the first interval), intracerebral microinfusions were made through a 28 -g 
injector (Semat Technical, UK) which was lowered to the site of injection, $2.5 \mathrm{~mm}$ below the guide cannula (core: $-7.2 \mathrm{~mm}$ DV; shell: $-7.8 \mathrm{~mm} \mathrm{DV}$ ). All infusions were of 0.5 microlitres over $90 \mathrm{~s}$ delivered to each side of the brain, using a syringe pump (Harvard Apparatus, Model \#975A), followed by a 90-s post-infusion diffusion time. Following all infusions, stylets were replaced, and the animal was left in a holding box for five minutes before testing. All rats received two "sham" infusions of phosphate-buffered water (PB) before testing, on separate days, to habituate the animal to the injection procedure (PB; composition $0.07 \mathrm{mM} \mathrm{Na}_{2} \mathrm{HPO}_{4}$, $0.028 \mathrm{mM} \mathrm{NaH}{ }_{2} \mathrm{PO}_{4}$, giving an approximate $\mathrm{pH}$ of 7.5). "Sham" injections were given prior to test sessions, following two days of stable responding.

Intra-cerebral infusions of the selective and competitive NMDA antagonist 2-amino-5-phosphonopentanoic acid (AP-5) were given following at least two days of stable responding subsequent to the "sham" infusions. D-(-)-2-Amino-Phosphonopentanoic Acid (AP-5) was obtained from Sigma, UK, and was dissolved in sterile PB. AP- 5 was given in four doses: PB, 1, 5 and $10 \mathrm{nmol}$ (equivalent to $0.2,1$ and 2 micrograms, respectively) according to a counterbalanced, Latin Square design, with infusions of each dose being separated by at least two days of stable responding without treatment.

The selective AMPA/KA antagonist LY293558 was given following at least two days of stable responding after the AP-5 doses. The compound (3SR, 4aRS, 6RS, 8aRS)-6-[2-(iH-tetrazol-5-yl)ethyl]-1,2,3,4,4a,5,6,7,8,8adecahydroiso-quinoline-3-carboxylic acid, LY293558, is the (-)-isomer of the racemic compound ( \pm ) LY 215490, is 10 fold selective for AMPA over NMDA receptors (Schoepp et al. 1995) and was a gift from Eli Lilly. LY293558 was dissolved in sterile $\mathrm{PB}$, aliquoted and frozen at $-5^{\circ} \mathrm{C}$ until use. Doses used were: $\mathrm{PB}, 0.0067,0.067$ and $0.67 \mathrm{nmol}$ (equivalent to $0.002,0.02$ and 0.2 micrograms). The order of doses was counterbalanced with a Latin Square design, and infusion of each dose was separated by at least two days of stable responding without treatment.

\section{Extinction}

To determine whether the effects of intra-cerebral infusions of AP-5 or LY293558 into the core or shell on responding for cocaine under a second-order schedule of reinforcement was qualitatively similar to saline substitution, a group of rats $(\mathrm{n}=10)$ was tested in extinction. Following training under the second-order schedule of reinforcement for cocaine with stable responding for at least 10 days, saline was substituted for seven days.

\section{Histological Assessment of Cannulae Placements}

At the end of testing, rats were anesthetized with an overdose of sodium pentobarbitone $(1.5 \mathrm{ml}$ per animal i.p., Euthatal, Rhone Merieux, UK) and perfused transcardially with isotonic saline, followed by $4 \%$ paraformaldehyde with $0.2 \%$ saturated picric acid in 0.2 $M$ phosphate buffer. Brains were then removed and post-fixed before being transferred to a $20 \%$ sucrose solution in $0.01 \mathrm{M}$ phosphate-buffered saline for about 24 hrs before being sectioned at 60 microns using a freezing microtome. Every third section was mounted, stained with Cresyl Violet and placements verified under a light microscope.

\section{Statistical Analyses}

For all self-administration sessions, the number of active and inactive lever presses was recorded during all five intervals. In addition, the total number and temporal pattern of cocaine infusions were also recorded. Bar presses on the active lever are presented as the mean \pm S.E.M. number of responses for each interval. Responding on the inactive lever is presented as the proportion of inactive/active lever presses per interval. Active lever presses were analyzed for all intervals to demonstrate the time course of the drug effects. The proportion of inactive/active lever presses was analyzed for the first and second intervals only.

Each day of extinction (substitution of cocaine by saline) was compared to the last day of cocaine selfadministration for each interval. For each interval, the saline substitution data are presented as mean \pm S.E.M number of responses and the mean \pm S.E.M. proportion of inactive/active lever presses for the seven days of saline substitution and the last day of self-administration before saline substitution. Data were analyzed with a one-way repeated-measures ANOVA and simple main effects. Criteria for significance was set at $p<.05$.

\section{RESULTS}

\section{Cannulae Placements}

Figure 1 illustrates the location of the tips of injection cannulae within the NAcc core (A) and shell (B). Two rats were excluded from the core analyses because the tips of their cannulae were not in the NAcc core. All other placements were in the core or shell as planned.

\section{Effects of Infusion of LY293558 into the NAcc Core on Responding for Cocaine under a Second-Order Schedule of Reinforcement}

Number of Active Lever Responses. During the first interval, following infusions of $0.067 \mathrm{nmol}$ and 0.67 nmol of LY293558 into the core, responding was substantially and significantly lower than was seen following PB treatment (Figure 2, Panel A). Simple main effects revealed a significant difference between the responding following $\mathrm{PB}$ and that following the 0.067 

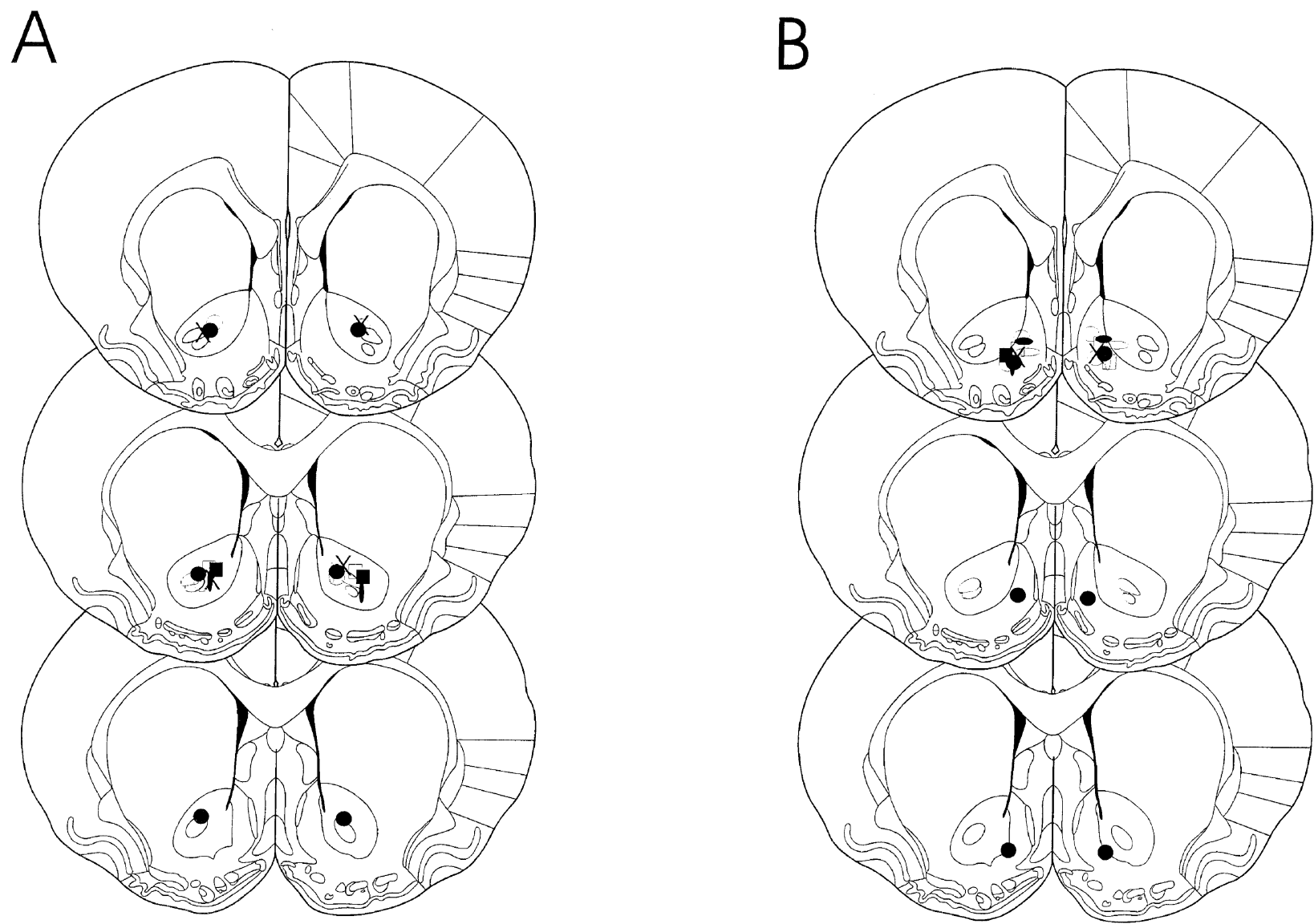

Figure 1. Location of the tips of injection cannulae within the NAcc core (Panel A) and shell (Panel B). Symbols represent the bilateral placement of the injections for each individual animal. Schematics of coronal sections are taken from Paxinos and Watson (1986).

nmol $(\mathrm{n}=8 ; \mathrm{F}(1,7)=16.2, p=.005)$ and $0.67 \mathrm{nmol}(\mathrm{F}(1$, $7)=9.334, p=.018$ ) doses. During the second interval, responding was higher, but its overall pattern following LY293558 infusion was similar to that observed during the first interval, i.e. responding decreased slightly following the $0.0067 \mathrm{nmol}$ dose, and continued to decrease further following the $0.067 \mathrm{nmol}$ and 0.67 nmol doses (Figure 2, Panel B). ANOVA revealed that there was a significant effect of LY293558 treatment on the rate of responding during the second interval (Figure 2, Panel B; $\mathrm{n}=8 ; \mathrm{F}(3,21)=4.63, p=.012$ ). Analysis of simple main effects revealed that responding following the 0.67 dose was significantly lower than that observed following PB (Figure 2, Panel B; $\mathrm{n}=8$ : $\mathrm{F}(1,7)=$ $16.204, p=.005)$. During the third, fourth and fifth intervals, responding following the $0.67 \mathrm{nmol}$ dose was also significantly different from that seen under $\mathrm{PB}$ (Figure 3, Panel A, B, C; $\mathrm{n}=8$; third: $\mathrm{F}(1,7)=21.7, p=$ .002 ; fourth: $\mathrm{F}(1,7)=14.38, p=.007$; fifth: $\mathrm{F}(1,7)=5.913$, $p=.045)$. The $0.067 \mathrm{nmol}$ dose was different from $\mathrm{PB}$ only during the third interval $(\mathrm{F}(1,7)=11.819, p=$ .011).
Inactive Lever Presses. One rat was excluded from the analysis (outlier test; value more than two standard deviations different from the rest of the group). During the first interval, inactive lever presses increased with the dose of antagonist administered. ANOVA revealed a significant effect of dose (Figure 4, Panel A; $\mathrm{n}=7$; $\mathrm{F}(3,18)=8.215, p=.012)$. In addition, the rate of inactive to active lever presses was significantly greater following the 0.067 and 0.67 doses than that seen following PB treatment (Figure 4, Panel A; for the 0.067 dose: $\mathrm{F}(1,6)=9.768, p=.020$; for the 0.67 dose: $\mathrm{F}(1,6)=6.25$, $p=.021$ ). During the second interval, the proportion of inactive to active lever presses was significantly different from PB for the 0.67 dose $(38.7 \pm 14 ; \mathrm{F}(1,6)=7.83$, $p=.031$ ). The effect of dose was just significant (Figure 4, Panel B; $\mathrm{F}(3,18)=4.97, p=.047)$.

\section{Effects of Infusion of AP-5 into the NAcc Core on Responding for Cocaine under a Second-Order Schedule of Reinforcement}

Number of Active Lever Responses. Following infusion of PB and three doses of AP-5 into the NAcc core, 
A First Interval

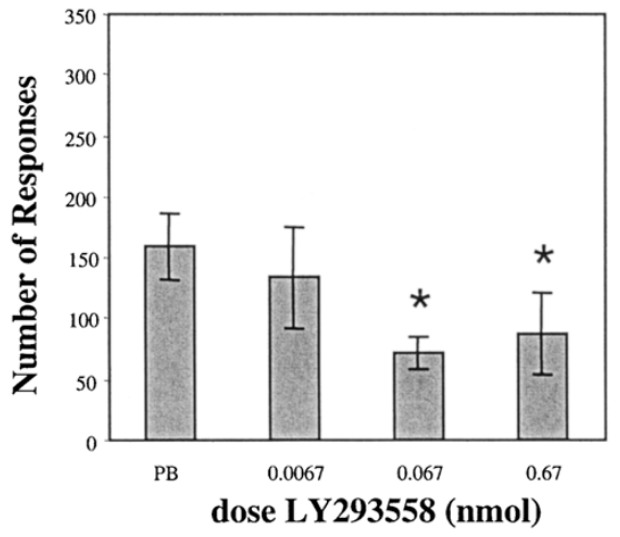

First Interval

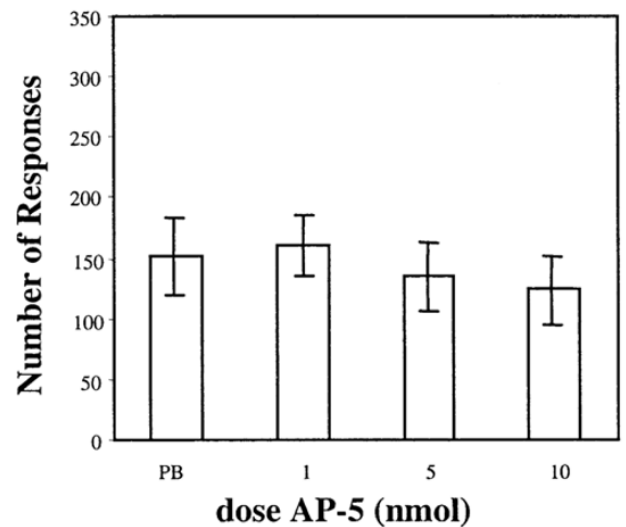

B Second Interval

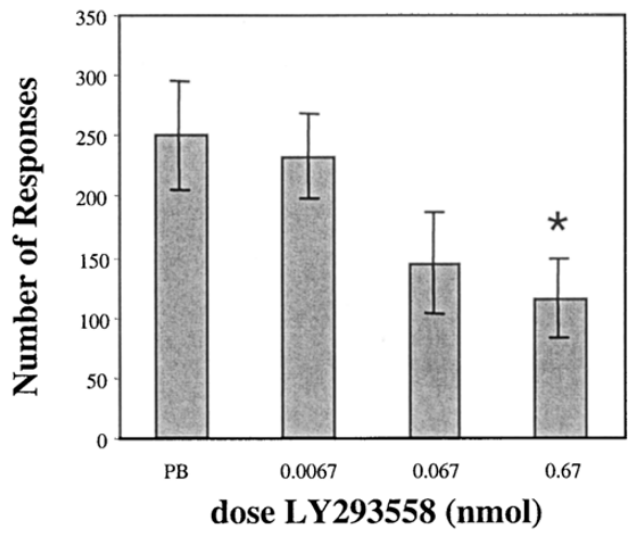

D Second Interval

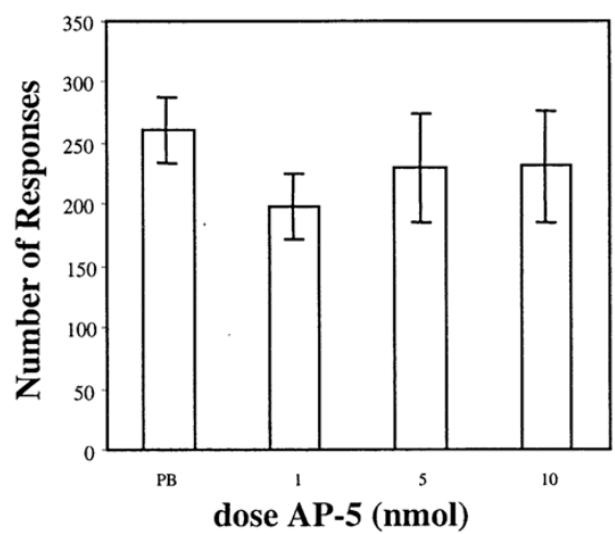

Figure 2. Mean number of responses ( \pm S.E.M.) under a second-order schedule of responding for cocaine during the first (Panel A) and second (Panel B) intervals following infusion of four doses of LY283558 ( $\mathrm{n}=8$; gray bars) into the NAcc core and during the first (Panel C) and second (Panel D) intervals following infusion of four doses of AP-5 (n = 14; open bars) into the NAcc core. *indicates where means were significantly different from PB.

mean number of responses were similar in all groups during the first interval (Figure 2, Panel C; $\mathrm{n}=14$ ). During the second interval, following a self-administered cocaine infusion, mean responding was similar at all doses but increased relative to those observed during the first interval (Figure 2, Panel D). In addition, mean responding during the third, fourth and fifth intervals remained elevated at $\sim 200$ to 300 responses per interval, following infusions of all doses of AP-5 (Figures 3, Panels D, E and F). No significant effects were revealed during any interval.

Inactive Lever Presses. During the first interval of responding, the mean ratio of inactive to active lever presses increased slightly above PB levels following in- fusion of the $5.0 \mathrm{nmol}$ and $10 \mathrm{nmol}$ doses into the NAcc core (Figure 4, Panel C; $\mathrm{n}=14$ ). Simple main effects revealed that responding following both these doses was significantly different from $\mathrm{PB}$ (for $5.0 \mathrm{nmol}$ : $\mathrm{F}(1,13)=$ $4.81, p=.047$; for 10.0 nmol: $\mathrm{F}(1,13)=6.35, p=.026)$. During the second interval no significant effects were revealed.

\section{Effects of Infusion of LY293558 into the NAcc Shell on Responding for Cocaine under a Second-order Schedule of Reinforcement}

Number of Active Lever Responses. During the first interval, there were no significant effects following LY29358 infused into the NAcc shell at any dose (Figure 5, Panel A; $\mathrm{n}=6$ ). There were also no effects of 

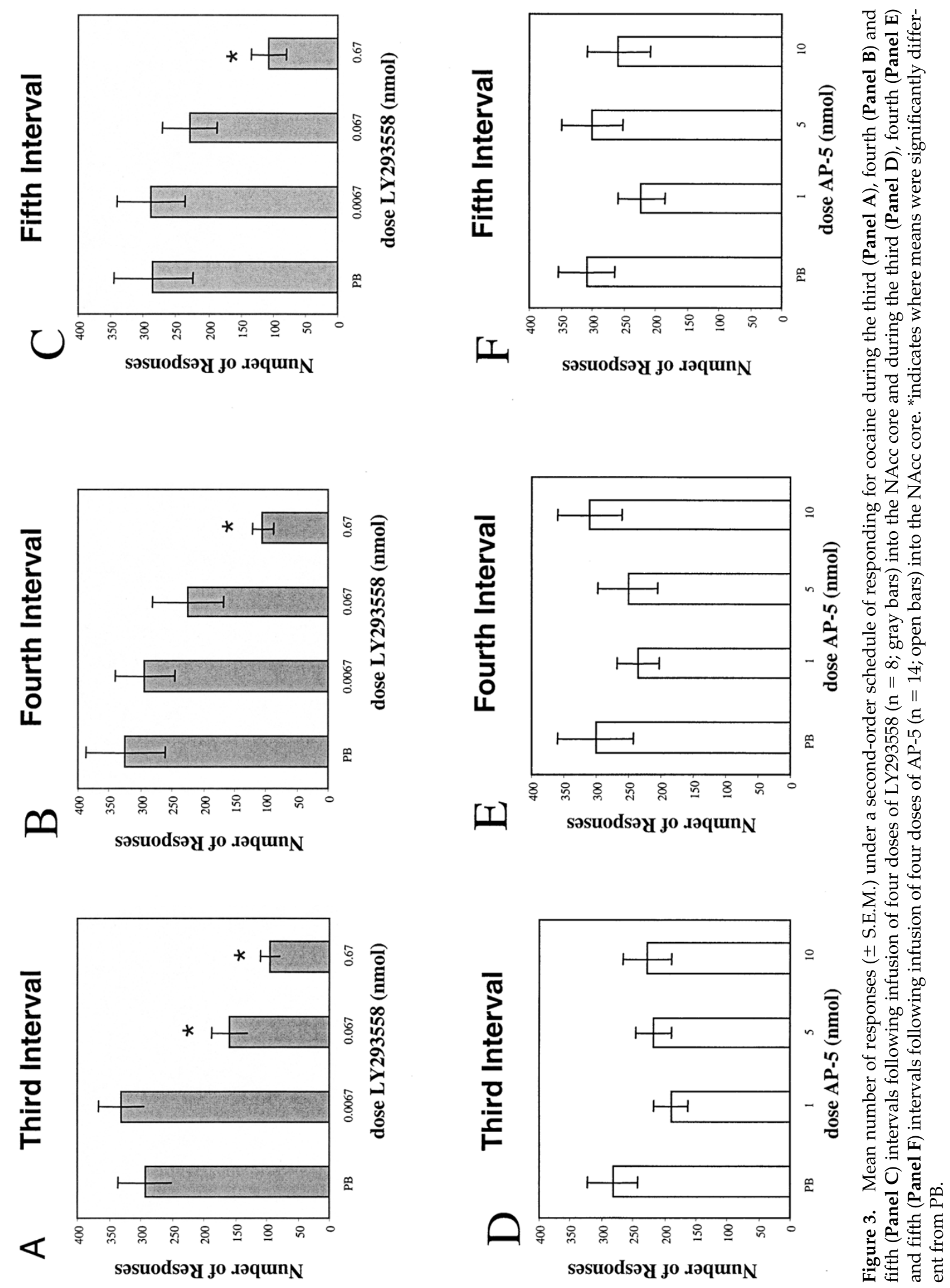
A First Interval
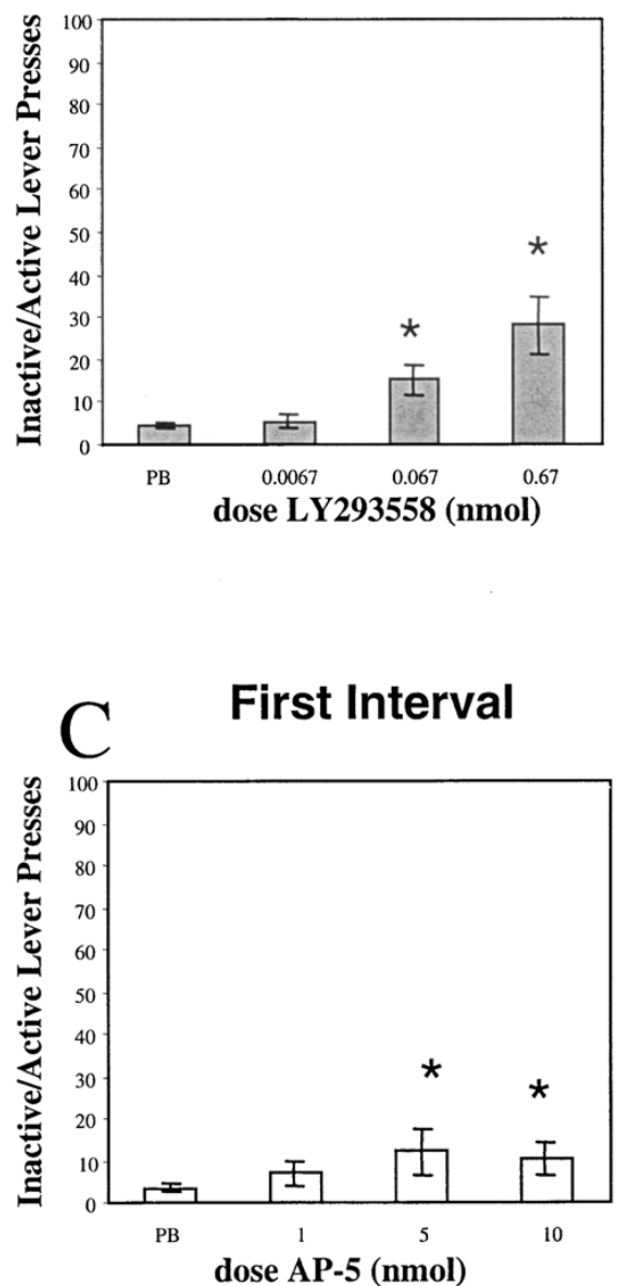

B Second Interval

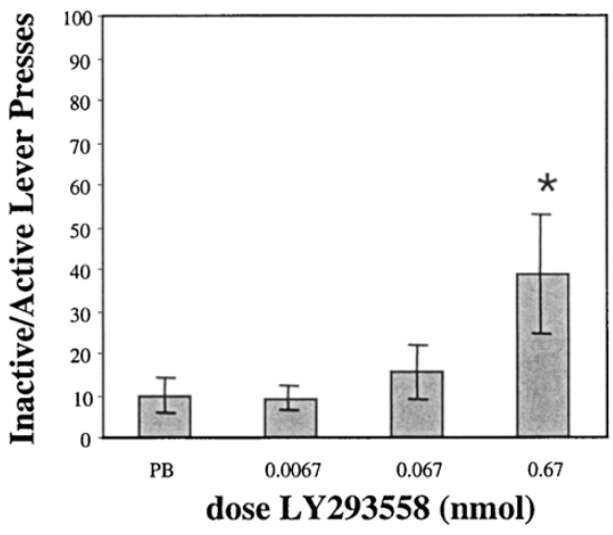

Second Interval

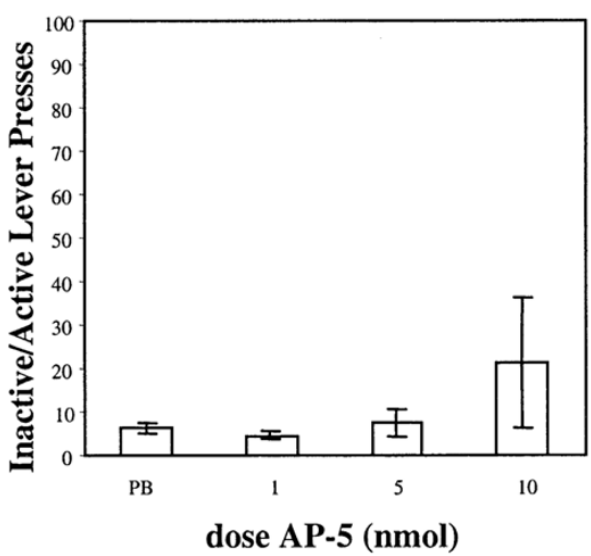

Figure 4. Mean proportion of inactive/active lever presses ( \pm S.E.M.) under a second-order schedule of responding for cocaine during the first (Panel A) and second (Panel B) intervals following infusion of four doses of LY293558 ( $\mathrm{n}=7$; gray bars) into the NAcc core and during the first (Panel C) and second (Panel D) intervals following infusion of four doses of AP-5 ( $n=14$; open bars) into the NAcc core. ${ }^{*}$ indicates where means were significantly different from PB.

LY293558 infused into the NAcc shell on the cocaine-induced increase in responding seen in the second interval (Figure 5, Panel B). During the third, fourth and fifth intervals, infusion of the highest dose of 0.67 was associated with lower levels of responding than those following PB (Figure 6, Panels A, B, C). ANOVA revealed a significant effect of dose $(\mathrm{F}(3,15)=5.448, p=$ .10) and simple main effects analysis revealed that the $\mathrm{PB}$ and 0.67 were just significantly different during the fourth interval $(\mathrm{F} 1,5)=6.39, p=.053)$.

Inactive Lever Presses. Analysis of the ratio of inactive to active lever presses during the first interval following infusion of LY293558 into the NAcc shell revealed a just significant effect of dose (Figure 7, Panel
$\mathrm{A} ; \mathrm{F}(3,15)=3.815, p=.049 ; \mathrm{n}=6)$. During the second interval, ANOVA revealed a significant effect of dose (Figure 7, Panel B; $\mathrm{n}=6$; $\mathrm{F}(3,15)=7.131, p=.035$ ). As well, the proportion of inactive to active lever presses was significantly different from $\mathrm{PB}$ at the $0.67 \mathrm{nmol}$ dose (Figure 7, Panel B; F(1,5) = 8.84, $p=.031$ ).

\section{Effects of Infusion of AP-5 into the NAcc Shell on Responding for Cocaine under a Second-order Schedule of Reinforcement}

Number of Active Lever Responses. During the first interval, infusion of AP-5 into the NAcc shell had no effect on responding at any dose (Figure 5, Panel C; $\mathrm{n}=$ 11). During the second interval, responding following infusion of AP-5 into the shell increased relative to that 

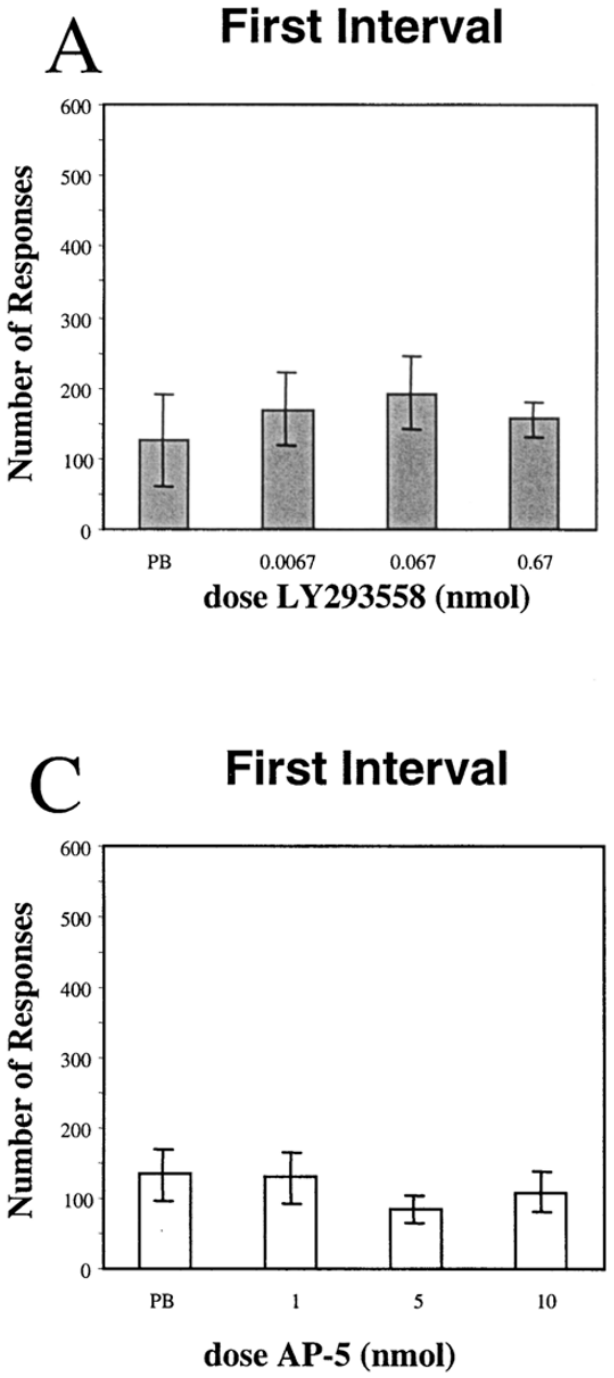
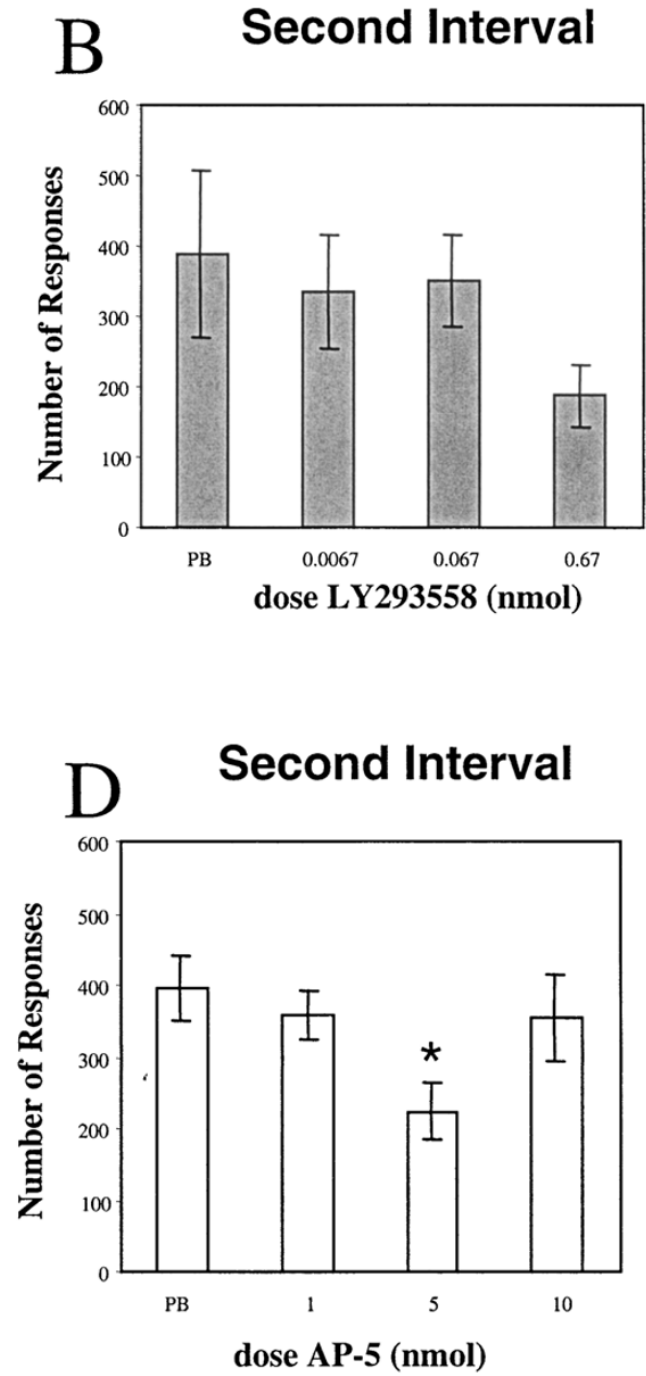

Figure 5. Mean number of responses ( \pm S.E.M.) under a second-order schedule of responding for cocaine during the first (Panel A) and second (Panel B) intervals following infusion of four doses of LY293558 ( $\mathrm{n}=6$; gray bars) into the NAcc shell and during the first (Panel C) and second (Panel D) intervals following infusion of four doses of AP-5 ( $\mathrm{n}=11$; open bars) into the NAcc shell. *indicates where means were significantly different from PB.

seen during the first interval (Figure 5, Panel D; $\mathrm{n}=11$ ). Responding decreased following the $5.0 \mathrm{nmol}$ dose, but was similar to PB following infusion of the $1.0 \mathrm{nmol}$ and $10.0 \mathrm{nmol}$ doses. Simple main effects revealed that responding under the $0.067 \mathrm{nmol}$ dose was significantly different from the PB dose (Figure 4, Panel G; F(1,10)= $7.45, p=.021)$. During the third, fourth and fifth intervals, mean responding was similar, at $\sim 300$ to 500 responses, following infusions of all doses of AP-5 into the NAcc shell. No significant effects were revealed (Figure 6, Panel D, E and F).

Inactive Lever Presses. During the first (Figure 7, Panel C) and second (Figure 7, Panel D) intervals of responding for cocaine under a second-order schedule of cocaine, the ratio of inactive to active lever presses was unaffected by any dose of AP-5. ANOVA revealed no significant effects.

\section{Extinction Following Substitution of Cocaine}

Active Lever Presses. During the first, third, fourth and fifth intervals, responding decreased on the first day of extinction when saline was substituted for cocaine as compared to the last day of self-administration before saline substitution (Figure 8). By the third day of saline substitution, responding had decreased to its lowest value in all intervals. The pattern of responding during the second interval was similar to the other intervals, except that responding increased non-significantly on the first day of saline substitution as com- 

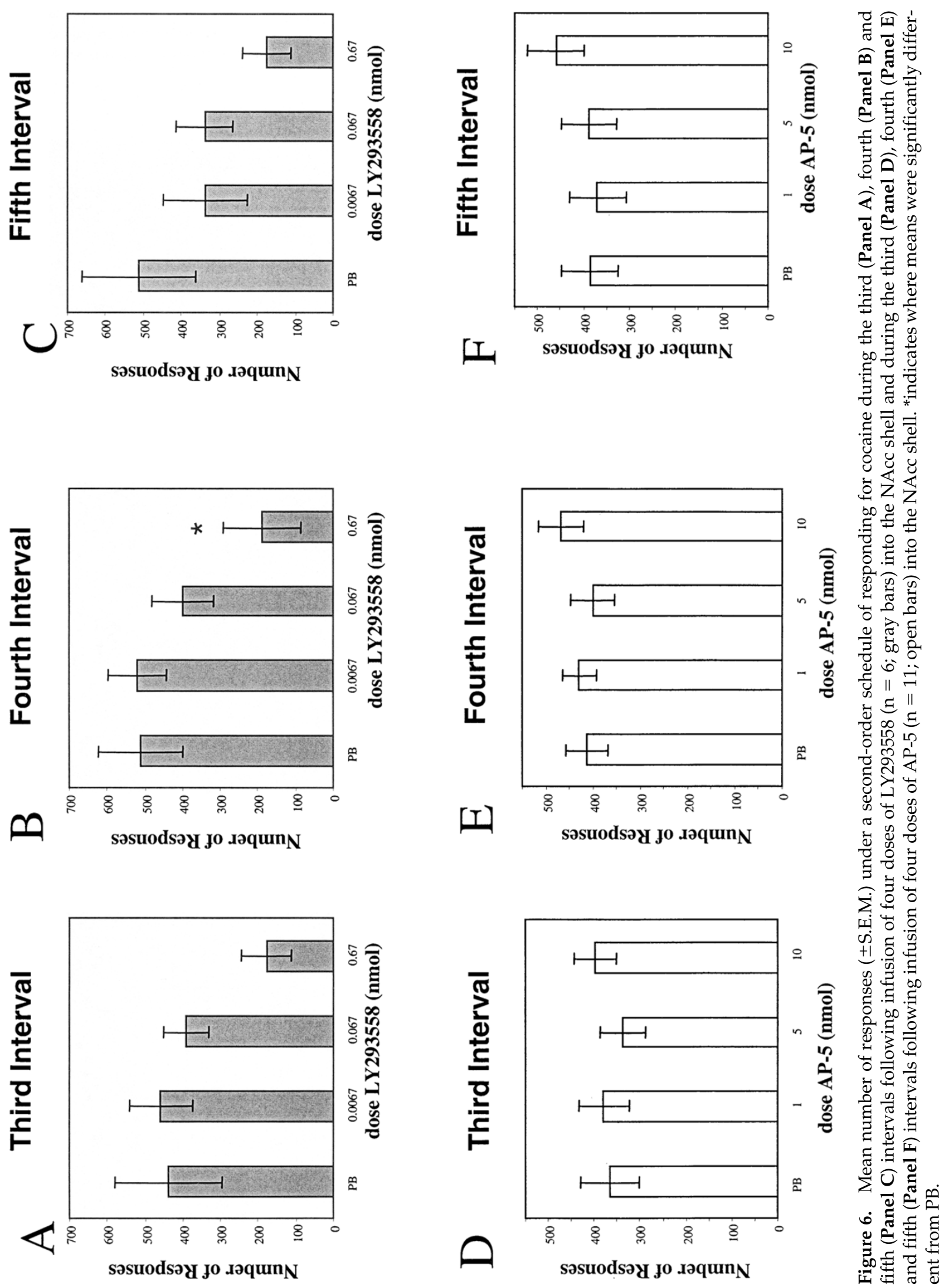

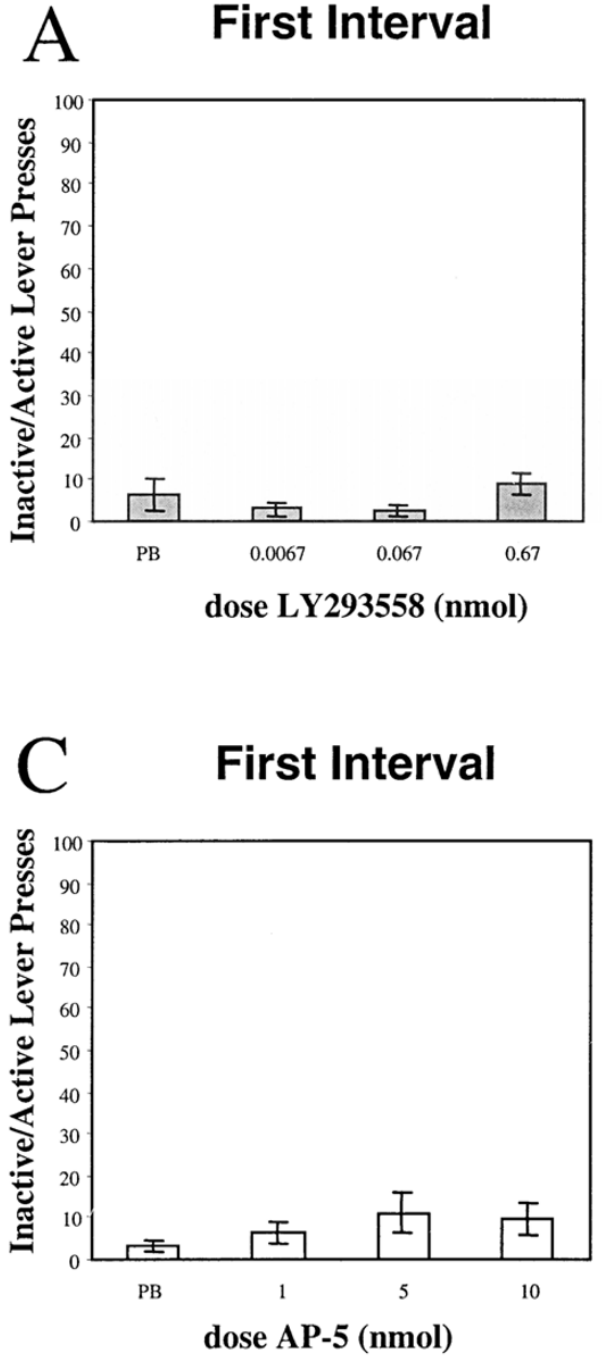
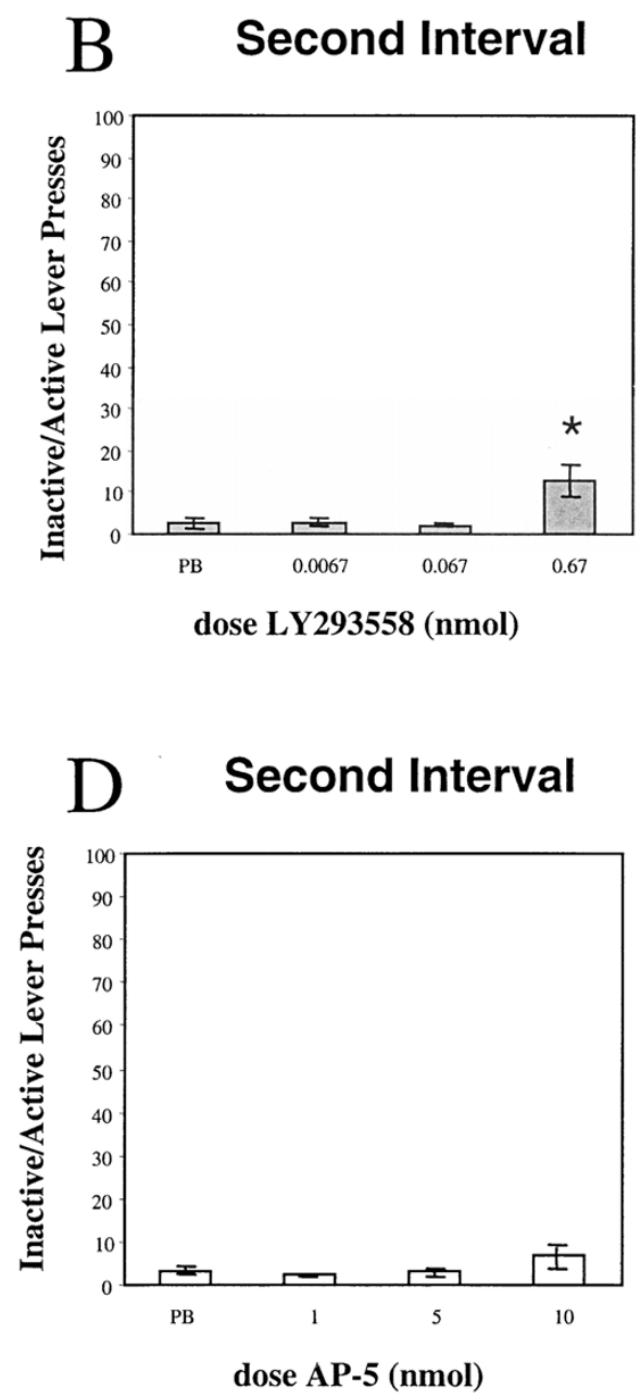

Figure 7. Mean proportion of inactive/active lever presses ( \pm S.E.M.) under a second-order schedule of responding for cocaine during the first (Panel A) and second (Panel B) intervals following infusion of four doses of LY293558 ( $\mathrm{n}=6$; gray bars) into the NAcc shell and during the first (Panel C) and second (Panel D) intervals following infusion of four doses of AP-5 ( $n=11$; open bars) into the NAcc shell. *indicates where means were significantly different from PB.

pared to the last day of self-administration. ANOVA revealed significant day effects for all intervals, indicating that responding decreased significantly over days following saline substitution $(\mathrm{n}=10$; first interval: $\mathrm{F}(7$, $56)=8.283, p=.005$; second: $\mathrm{F}(7,56)=11.22, p=.000$; third: $\mathrm{F}(7,56)=7.206, p=.000$; fourth: $\mathrm{F}(7,56)=3.323$, $p=.036$; fifth: $\mathrm{F}(7,56)=2.812, p=.042)$. $\mathrm{F}$ and $p$ values of simple main effects on the last day of self-administration compared to each day of saline substitution are presented in Table 1 for each interval.

Inactive Lever Presses. During extinction the ratio of inactive to active lever presses was similar across days (Figure $9 ; n=10$ ). ANOVA revealed that the ratio of inactive to active lever presses was just significantly dif- ferent from the last day of self-administration during the second interval of day $2(\mathrm{~F}(1,9)=5.225, p=.048)$ and during the third interval of day 3 only $(\mathrm{F}(1,9)=$ $5.161, p=.049)$, indicating that the ratio of inactive/active lever presses did not change following saline substitution.

\section{DISCUSSION}

We have investigated the involvement of ionotropic glutamate receptor subtypes in the NAcc core and shell in cue-controlled drug-seeking behavior by infusing NMDA and AMPA/KA receptor antagonists into these sub-regions in rats responding under a second-order 
A

First Interval

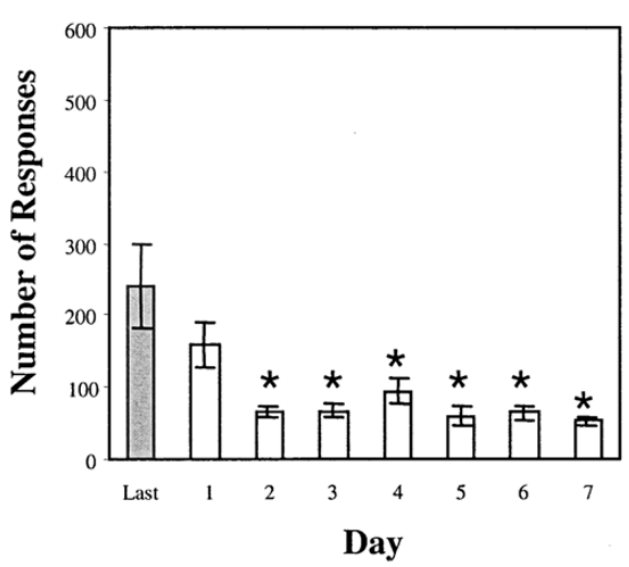

C Third Interval
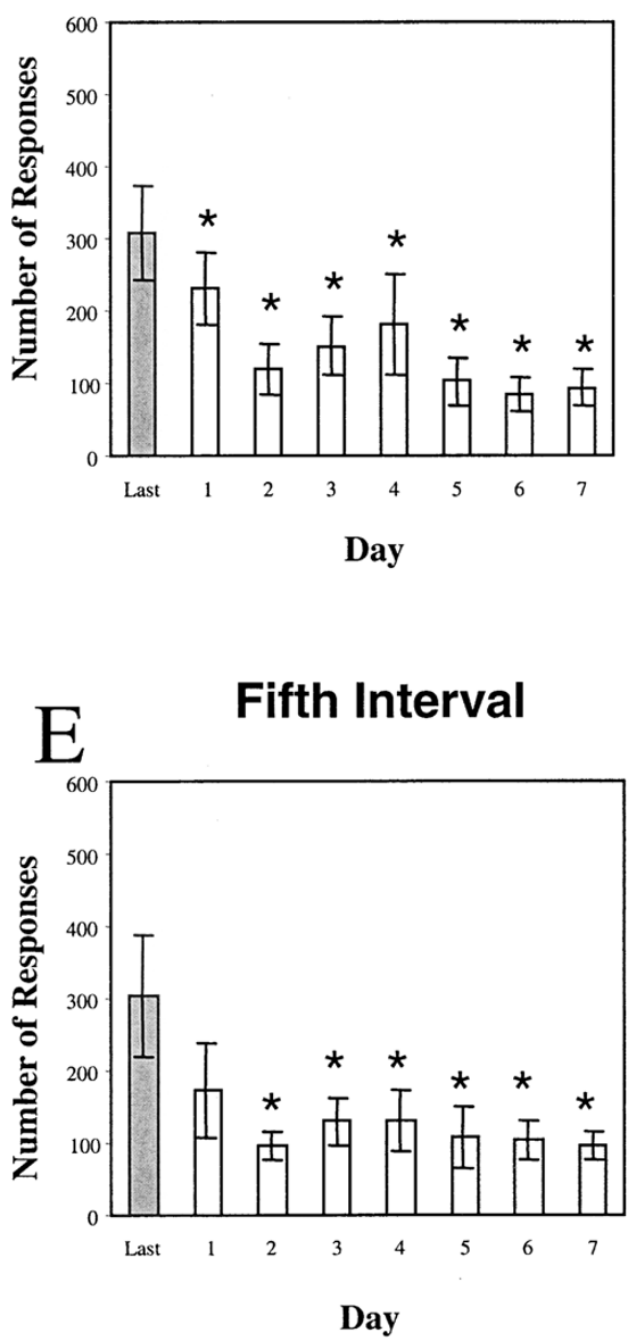

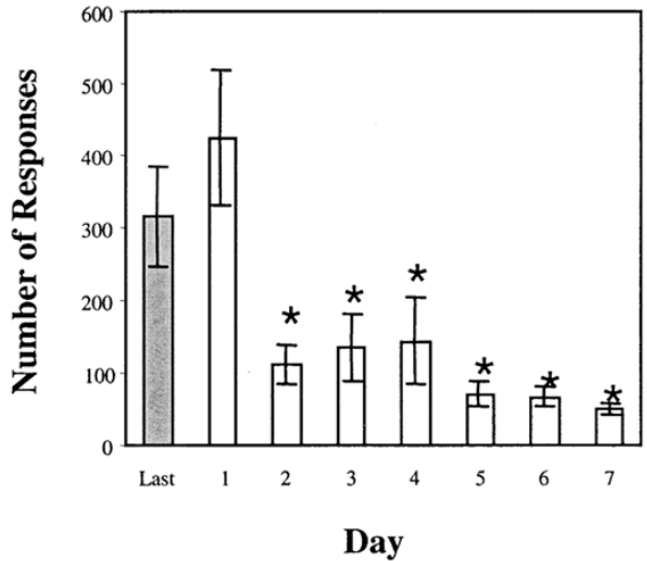

D Fourth Interval

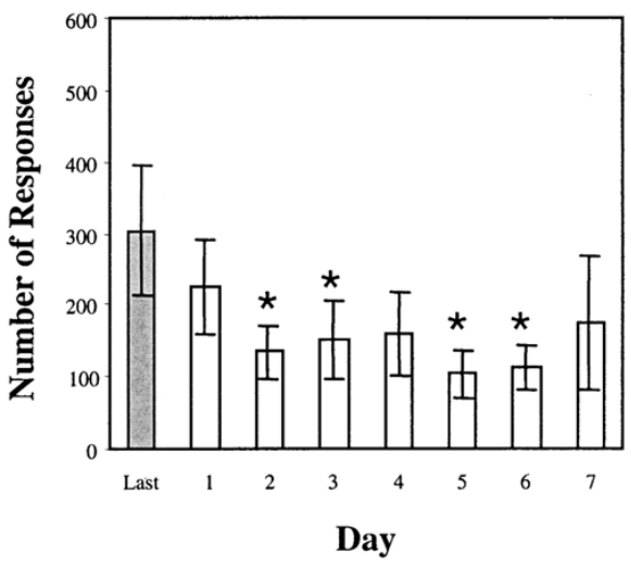

Figure 8. Mean number of responses ( \pm S.E.M.) during the first (Panel A), second (Panel B), third (Panel C), fourth (Panel D) and fifth (Panel E) intervals of responding under a second-order schedule during seven days of extinction by substitution of cocaine with saline $(n=10)$. *indicates where means during extinction (open bars) were different from the last day of cocaine self-administration (gray bars). 
A

First Interval

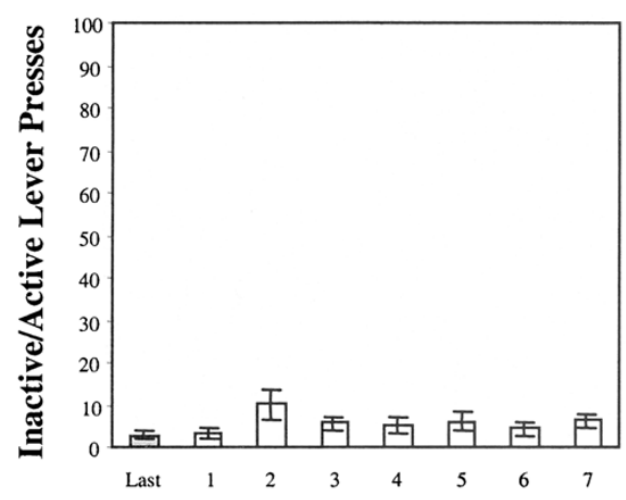

Day

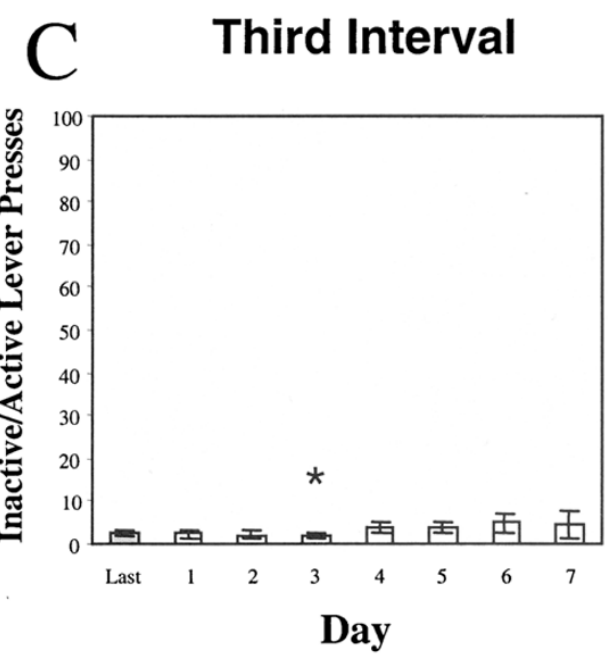

E Fifth Interval

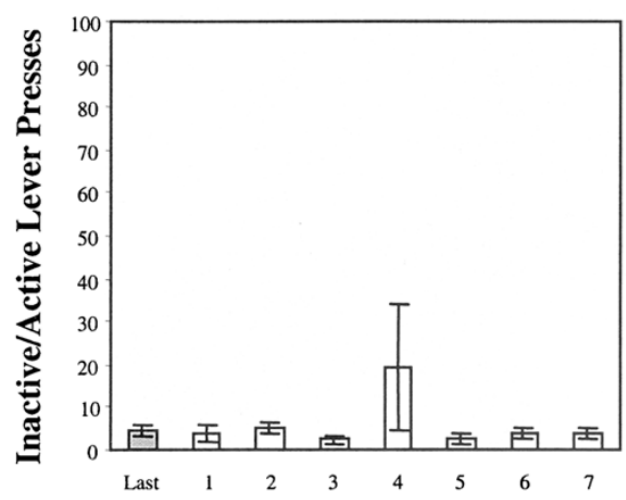

Day
B Second Interval

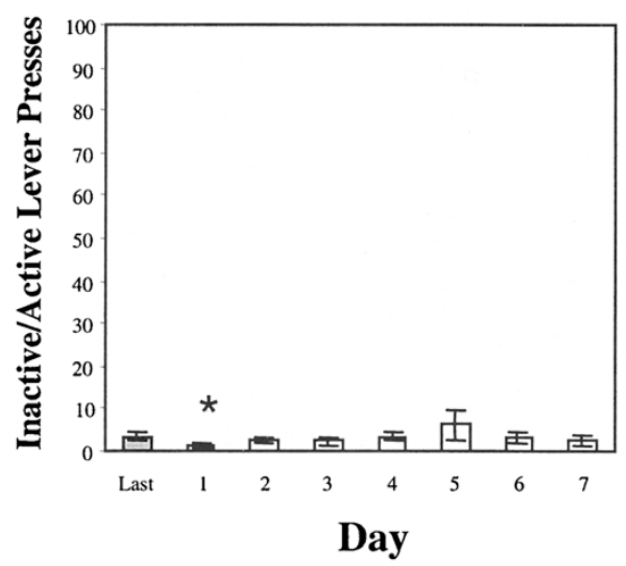

D

Fourth Interval

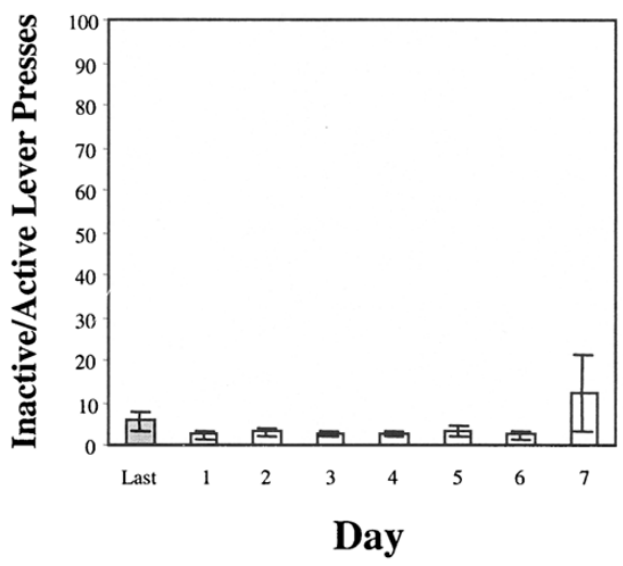

Figure 9. Mean proportion of inactive/active lever presses ( \pm S.E.M.) during the first (Panel A), second (Panel B), third (Panel C), fourth (Panel D) and fifth (Panel E) intervals of responding under a second-order schedule during seven days of extinction by substitution of cocaine with saline $(n=10)$. *indicates where means during extinction (open bars) were different from the last day of cocaine self-administration (gray bars). 
Table 1. Simple Main Effects of Comparison of Responding on The Last Day of Self-Administration and Each Day of Extinction for Each Interval

\begin{tabular}{clllll}
\hline Day & $\mathbf{1}^{\text {st }}$ Interval & $\mathbf{2}^{\text {nd }}$ Interval & $\mathbf{3}^{\text {rd }}$ Interval & $\mathbf{4}^{\text {th }}$ Interval & $\mathbf{5}^{\text {th }}$ Interval \\
\hline $1^{\text {st }}$ & $\mathrm{F}=4.80$, & $\mathrm{F}=3.402$ & $\mathrm{~F}=16.588$ & $\mathrm{~F}=.824$ & $\mathrm{~F}=2.526$ \\
& $\mathrm{p}=0.056$ & $\mathrm{p}=0.098$ & $\mathrm{p}=0.003^{*}$ & $\mathrm{p}=0.388$ & $\mathrm{p}=0.157$ \\
$2^{\text {nd }}$ & $\mathrm{F}=11.092$ & $\mathrm{~F}=10.604$ & $\mathrm{~F}=10.154$ & $\mathrm{~F}=5.942$ & $\mathrm{~F}=7.401$ \\
& $\mathrm{p}=0.009^{*}$ & $\mathrm{p}=0.010^{*}$ & $\mathrm{p}=0.011^{*}$ & $\mathrm{p}=0.038^{*}$ & $\mathrm{p}=0.024^{*}$ \\
$3^{\text {rd }}$ & $\mathrm{F}=9.809$ & $\mathrm{~F}=8.199$ & $\mathrm{~F}=10.477$ & $\mathrm{~F}=6.887$ & $\mathrm{~F}=7.438$ \\
& $\mathrm{p}=0.012^{*}$ & $\mathrm{p}=0.019^{*}$ & $\mathrm{p}=0.010^{*}$ & $\mathrm{p}=0.028^{*}$ & $\mathrm{p}=0.023^{*}$ \\
$4^{\text {th }}$ & $\mathrm{F}=7.838$ & $\mathrm{~F}=11.218$ & $\mathrm{~F}=9.223$ & $\mathrm{~F}=4.947$ & $\mathrm{~F}=9.808$ \\
& $\mathrm{p}=0.023^{*}$ & $\mathrm{p}=0.010^{*}$ & $\mathrm{p}=0.016^{*}$ & $\mathrm{p}=0.057$ & $\mathrm{p}=0.014^{*}$ \\
$5^{\text {th }}$ & $\mathrm{F}=9.728$, & $\mathrm{F}=24.542$ & $\mathrm{~F}=26.8$ & $\mathrm{~F}=6.789$ & $\mathrm{~F}=12.324$ \\
& $\mathrm{p}=0.014^{*}$ & $\mathrm{p}=0.001^{*}$ & $\mathrm{p}=0.001^{*}$ & $\mathrm{p}=0.031^{*}$ & $\mathrm{p}=0.008^{*}$ \\
$6^{\text {th }}$ & $\mathrm{F}=11.227$, & $\mathrm{F}=16.715$ & $\mathrm{~F}=28.149$ & $\mathrm{~F}=10.547$ & $\mathrm{~F}=9.575$ \\
& $\mathrm{p}=0.009^{*}$ & $\mathrm{p}=0.003^{*}$ & $\mathrm{p}=0.000^{*}$ & $\mathrm{p}=0.010^{*}$ & $\mathrm{p}=0.013^{*}$ \\
$7^{\text {th }}$ & $\mathrm{F}=10.525$, & $\mathrm{F}=18.470$ & $\mathrm{~F}=13.254$ & $\mathrm{~F}=3.753$ & $\mathrm{~F}=9.222$ \\
& $\mathrm{p}=0.010^{*}$ & $\mathrm{p}=0.002^{*}$ & $\mathrm{p}=0.005^{*}$ & $\mathrm{p}=0.085$ & $\mathrm{p}=0.014^{*}$ \\
\hline
\end{tabular}

schedule of cocaine reinforcement. When infused into the NAcc core, the selective AMPA/KA receptor antagonist LY293558 dose-dependently decreased cocaineseeking behavior both in the first, drug-free interval and subsequent intervals of a session. Infusion of LY293558 into the shell was without effect. By contrast, the NMDA receptor antagonist, AP-5, was without effect on cocaineseeking behavior when infused into the core, while infusion into the shell resulted in a limited effect of decreasing responding during the second interval only.

\section{The Effects of AMPA/KA Receptor Antagonism in the Nucleus Accumbens Core and Shell}

Under the second-order schedule of reinforcement used in the present study, responding during the first interval of a session provides a measure of drug-seeking behavior that depends in part upon the reinforcing efficacy of the to-be self-administered cocaine and not its other (e.g. response rate-altering) effects. Responding is also dependent upon the contingent presentations of a cocaine-associated cue upon completion of each FR10 of responses comprising the unit (or component) schedule (Arroyo et al. 1998; Everitt and Robbins 2000). Omission of the CS has been shown to result in a marked decrease in responding (Arroyo et al. 1998), emphasizing its importance in maintaining drug-seeking behavior. Thereafter, other behavioral effects of self-administered cocaine that are not necessarily related to its reinforcing efficacy also influence responding. These characteristics of responding under a second-order schedule of reinforcement are important as they suggest that the decrease in responding during the first interval that followed intra-core infusions of LY293558 reflects an attenuation of the role of the CS in sustaining cocaineseeking behavior.

As we have reported previously, responding during the second interval was increased compared to the first interval as a result of the self-administration of cocaine (Arroyo et al. 1998; Cador et al. 1989; Everitt and Robbins 2000; Pilla et al. 1999; Whitelaw et al. 1996). This potentiative effect of cocaine on drug-seeking responses is consistent with data showing that the control over instrumental behavior by a conditioned reinforcer is potentiated by stimulant drugs acting specifically in the NAcc (Parkinson et al. 1999; Taylor and Horger 1999; Taylor and Robbins 1984, 1986). The additional finding that infusion of LY293558 into the core decreased responding during the second and subsequent intervals may at first sight indicate that blockade of non-NMDA receptors in the NAcc core attenuated the potentiative effects of cocaine on behavior maintained by a CS. However, LY293558 produced proportionally the same decrease in responding during both the first and second intervals. This observation, together with that showing infusion of the AMPA/KA receptor antagonist CNQX into the whole NAcc blocked conditioned reinforcement and thereby amphetamine-potentiated conditioned reinforcement (Burns et al. 1994), suggests that the effects of non-NMDA receptor blockade in the present study were related more to a disruption of the effects of the CS in maintaining responding than to a decrease in the effects of self-administered cocaine.

Glutamatergic drugs have well-documented effects on locomotor activity, perhaps indicating that the change in responding produced by infusion of intraNAcc core LY293558 in the present study reflected more general alterations in motor activity. For example, AMPA/KA receptor antagonists infused directly into the NAcc typically increase spontaneous motor activity (Boldry et al. 1992; Burns et al. 1994; Roozendaal et al. 1990), whereas CNQX infused into the NAcc blocked $d$-amphetamine potentiated locomotion (Burns et al. 1994). However, these studies did not specifically target the NAcc core and it has been demonstrated that infusions into the entire NAcc may produce different effects 
from more specific infusions into the core (Burns et al. 1994; Maldonaldo-Irizarry and Kelley 1994). Thus, the precise involvement of AMPA/KA receptors in the NAcc core in the control of locomotor activity remains unclear.

However, the present finding that responding on the active lever decreased, whereas that on the inactive lever increased, following infusion of LY293558 into the NAcc core suggests that its effects cannot be explained by simple decreases or increases in motor activity. Indeed, it has been reported that infusion of the AMPA/ $\mathrm{KA}$ receptor antagonist $\mathrm{CNQX}$ into the NAcc decreased reinstatement of cocaine-induced cocaine-seeking behavior without affecting cocaine-induced locomotion (Cornish and Kalivas 2000), while AMPA receptor stimulation increased reinstatement of drug-seeking without increasing inactive lever responses (Cornish et al. 1999). This further suggests that the effects of nonNMDA receptor antagonists on motor activity and drug-seeking behavior may be dissociable. Strong support for this suggestion is provided by the observation that CNQX infused generally into the NAcc decreased conditioned reinforcement, yet increased spontaneous locomotor activity (Burns et al. 1994). Therefore, following infusion of LY293558 into the core, the observation that the proportion of inactive to active lever presses was affected dose-dependently and paralleled the decrease in active lever presses, points to the more likely conclusion that blockade of non-NMDA receptors in the NAcc core reduced the conditioned stimulus control over drug-seeking behavior.

A body of literature now exists implicating AMPA/ KA receptors in processes that are believed to be related to drug abuse. Apart from disrupting the self-administration of ethanol (Stephens and Brown 1999), the AMPA/KA receptor antagonist NBQX also disrupted the expression of behavioral sensitization to amphetamine (Jackson et al. 1998; Li et al. 1997; Mead and Stephens 1998). A specific role for AMPA receptors in conditioned reinforcement is suggested by findings that DNQX blocked the expression of a cocaine-induced place preference when administered into the NAcc (Kaddis et al. 1995) or intracerebroventricularly (Cervo and Samanin 1995). When infused intracerebroventricularly, AMPA/KA receptor antagonists also decreased conditioned locomotion (Cervo and Samanin 1996). The further finding that AMPA/KA receptor antagonists decreased both active and inactive lever presses during the self-administration of cocaine, suggests that the effects of AMPA/KA antagonists on cocaine reinforcement may be somewhat non-specific. This further supports the present hypothesis that the decreases in responding observed during the second interval following infusion of LY293558 into the core were related more to the ability of the CS to control behavior than to an attenuation of the effects of cocaine per se.

\section{The Effects of NMDA Receptor Antagonism in the Core and Shell}

The observation that AP-5 infused into the NAcc core had no significant effect on cocaine-seeking behavior is consistent with the report that the same drug infused into the whole NAcc had no effect on the reinstatement of cocaine-induced cocaine-seeking behavior (Cornish and Kalivas 2000), and also supports the findings that systemic (Cervo and Samanin 1995, 1996) or intra-cerebroventricular (Druhan and Wilent 1999) administration of NMDA receptor antagonists had no effect on the expression of a conditioned place preference. These data are perhaps somewhat surprising given the observation that AP-5 infusions into the NAcc reduced (Maldonaldo-Irizarry and Kelley 1994) or increased (Burns et al. 1994; Cornish and Kalivas 2000) spontaneous locomotion and increased responding for cocaine under a FR-1 schedule (Pulvirenti et al. 1992). Indeed, significant, albeit small, increases in the proportion of inactive/active lever presses were seen during the first interval of responding after AP-5 infusion into the core. If inactive lever presses can be used as a measure of more general motor activation, this observation can be interpreted to indicate that antagonism of NMDA receptors in the core increases motor activity, as suggested by Cornish and Kalivas (2000). However, since these increases were not accompanied by an increase in active lever presses, a measure of drug-seeking, these findings instead provide stronger support for the suggestion made above that the effects of intra-NAcc AMPA/KA and NMDA receptor antagonists on motor activity may be dissociable from those on drug-seeking behavior. This is also indicated by the observation that infusion of AP-5 into the NAcc increased spontaneous locomotor activity, but had no effect on conditioned reinforcement (Burns et al. 1994). Indeed, recent data suggest that NMDA receptors in the NAcc core may subserve a general motivational role. For example, intra-core infusions of NMDA receptor antagonists abolished the reduction in reaction time to respond for stimuli predictive of high reward magnitude, as compared to the reaction time to respond for cues predictive of smaller rewards (Hauber et al. 2000).

Infusion of the NMDA receptor antagonist AP-5 into the shell produced decreases in responding during the second interval only. Since these changes were not associated with changes in the proportion of inactive/active lever presses, they are difficult to interpret as being a result of general changes in motor activity, or in the ability of the CS to control responding, as discussed above. Moreover, since the effects were selective to the second interval only, it suggests that the effects of AP-5 infused into the shell were on the potentiative effect of cocaine on responding maintained by a CS. Indeed, AP-5 infused into the entire NAcc decreased only the po- 
tentiation of conditioned reinforcement by amphetamine and not conditioned reinforcement itself (Burns et al. 1993). The transient nature of this effect may reflect the short time course of action of AP-5. Indeed, when doses similar to the lower ones used in the present study were infused generally into the NAcc (Burns et al. 1994), or into the shell (Pulvirenti et al. 1994), increases in spontaneous motor activity lasted for only 20 or 30 minutes, which is the time needed to complete the first two ratio requirements in the second-order schedule used here.

Interpretation of the results of studies measuring the effects of intra-cerebral infusions on behavior depends upon the extent of drug diffusion from the site of infusion. In the present study, differences were observed in the effects of LY293558 when infused into the core as compared to the shell, indicating that the infusions produced anatomically specific effects on behavior. That is, dramatic changes were observed when LY293558 was infused into the core, whereas effects when infused into the shell were small and transient. Specifically, core infusions produced robust dose-dependent decreases in responding in all intervals, and dose-dependent increases in the proportion of inactive/active lever presses. Infusion into the shell was associated with a decrease in responding that was observed only at the highest dose and reached significance only in the fourth interval. A small but significant increase in the inactive/active lever presses was also observed at the highest dose in the second interval only. Given that this small, nearly-significant shadowing of the effects of core infusions was only observed at the highest dose, it cannot be excluded that these minor effects of LY293558 infused into the shell were due to diffusion of the drug medially into the core.

The lack of effect on drug-seeking behavior of infusing drugs into the shell may in part be a consequence of implanting the cannulae vertically, thereby compromising the lateral ventricles to produce a low resistance conduit for reflux of the infused drugs. However, we suggest that this explanation is unlikely because using identical procedures we have shown robust effects of amphetamine infusions into the shell to increase responding with conditioned reinforcement (Parkinson et al. 1999), while similarly large effects were also seen by Wyvell and Berridge (2000), again using vertical cannulae. Most importantly, a number of studies have demonstrated behavioral effects of intra-shell infusion of GABA-ergic (Stratford and Kelley 1997) and glutamatergic (Stratford et al. 1998) drugs through vertical cannulae at stereotaxic coordinates similar to those used in the present study. It should be noted that in the present study the $5 \mathrm{nmol}$ dose of AP- 5 decreased response rates during the second interval only, indicating that the drug was effective when infused into the shell. Moreover, the fact that this drug was without effect when infused into the core further emphasizes the differential contribu- tion of core and shell subregions to cue-controlled behavior.

\section{Extinction by Substitution of Cocaine by Saline}

Decreases in responding under a second-order schedule of cocaine self-administration are seen in extinction, that is when cocaine infusions are replaced by saline (Arroyo et al. 1998). We therefore compared the decline of responding under extinction with the effects of infusions of LY293558 into the core. There was a significant decrease in responding on the second day of extinction, but no change during the first day, confirming our earlier results (Arroyo et al. 1998). These decreases in responding during extinction were also not accompanied by an increase in the proportion of inactive/active responses. Thus, the effects of extinction were qualitatively different from the effects of LY293558 infused into the core lending further support to the suggestion that the effects of non-NMDA receptor blockade in the core were due to the prompt diminution in the effects of the response-contingent cocaine cue to maintain drugseeking behavior, rather than any interference with the reinforcing effects of cocaine. The fact that the effect of LY293558 was seen in the first interval, before cocaine was self-administered, also encourages this view.

\section{The Core and Shell Form Part of Functionally Dissociable Neuroanatomical Systems}

The present results support and extend recent findings suggesting that the NAcc core and shell form part of dissociable neural systems. For example, the core receives prominent afferent projections from the anterior cingulate cortex and BLA, structures that have been shown to be involved in the control over behavior by conditioned stimuli (Everitt et al. 1999). Imaging studies implicate a role for both of these structures in that both the anterior cingulate cortex and amygdala show increased activity when cocaine and heroin abusers are exposed to drug-associated cues that elicit craving (Childress et al. 1999). Further, in rats, bilateral lesions of the anterior cingulate cortex or the NAcc core, or their disconnection using an asymmetric lesion procedure, impair discriminated approach to a stimulus paired with reward in an autoshaping task that measures appetitive pavlovian conditioning (Bussey et al. 1997; Parkinson et al. 1999, 2000a, 2000b). Therefore, disruption of cue-controlled behavior in the present study following administration of AMPA/KA antagonists into the NAcc core may reflect a disruption of discriminated approach to an appetitive CS by interfering with the projections from the anterior cingulate cortex to the Nacc core.

Animal studies also implicate the BLA in some of the processes involved in addictive behavior, for example 
lesions of the BLA impaired the acquisition of responding for cocaine under a second-order schedule of reinforcement, while not affecting the primary reinforcing effects of cocaine (Whitelaw et al. 1996). Moreover, tetrodotoxin infused into the BLA (Grimm and See 2000), or lesions of this structure (Meil and See 1997) blocked cue-induced reinstatement of drug-seeking behavior while having no effect on cocaine-induced reinstatement of drug-seeking. Taken together, these findings are consistent with the notion that processing of information about drug-associated cues in the anterior cingulate cortex and BLA is transferred via their glutamatergic projections to the NAcc, especially the core, to gain access to response selection mechanisms (Parkinson et al. 1999, 2000a). The effects of infusion of LY293558 into the core seen in the present study strongly suggest that AMPA/KA receptors play a critical role in mediating these associative limbic cortical influences on cue-controlled cocaine-seeking behavior.

\section{Glutamate-dopamine Interactions in the Nucleus Accumbens}

Indirect evidence from converging sources suggests that DA and glutamate receptors may interact in these reward-related processes. Both NMDA and AMPA increase NAcc DA efflux, a change which is associated with increases in motor activity (Svensson et al. 1994). Stimulation of the subiculum or BLA increased DA efflux in the NAcc and this was blocked by ionotropic glutamate receptor antagonists (Blaha et al. 1997; Floresco et al. 1998). In addition, locomotor activity induced by intra-NAcc infusions of NMDA and AMPA was attenuated by DA receptor antagonists, suggesting that glutamate-induced increases in motor activity may be mediated by DA (Wu et al. 1993). The converse is also true in that AP-5 and CNQX inhibit cocaine-induced increase in DA when administered through a dialysis probe, with no effects on basal levels of DA (Pap and Bradberry 1995). Modulation of DA efflux by AMPA/KA receptors may importantly affect processes underlying addictive behavior since, for example, CNQX infused into the NAcc blocked drug-seeking behavior induced by intra-NAcc infusions of DA (Cornish and Kalivas 2000). Together, these findings suggest that NMDA and AMPA/KA receptors may alter responding for cocaine under a second-order schedule of reinforcement by attenuating potentiated DA efflux.

It may further be postulated that the efficacy of glutamate receptor antagonists to decrease cocaineseeking behavior may be related to differences in the regulation of DA efflux in the core and shell. It has been demonstrated that psychostimulants induce larger increases in DA efflux in the shell, as compared to the core (Barrot et al. 1999; Pierce and Kalivas 1995; Pontieri et al. 1995). By contrast, DA is increased preferentially in the core following response-independent presentations of a drug-paired CS (Ito et al. 2000). Since LY293558 infusion into the core resulted in a reduction in the ability of the drug-paired CS to control responding, this effect may depend upon a reduction in the conditioned increases in NAcc DA that are induced by presentations of drug-paired stimuli (Di Ciano et al. 1998a, 1998b; Gratton and Wise 1994; Kiyatkin and Stein 1996).

The precise psychological processes affected by manipulation of AMPA receptors in the NAcc core remains to be established. Disruption of the conditioned reinforcing effects of the drug cue, or its ability to amplify instrumental behavior (Lovibond 1983) through modulation of the DA-dependent processes of attribution of incentive salience to a stimulus (Wyvell and Berridge 2000; Berridge and Robinson 1998), are all candidate processes. But in each case, the present data support the hypothesis that glutamatergic afferents from cortical sites mediating these various associative influences on drug-seeking behavior converge on response mechanisms within the NAcc core.

\section{ACKNOWLEDGMENTS}

Supported by an MRC program grant (G9537855) to B.J.E. and an MRC Co-operative: Brain, Behaviour and Neuropsychiatry. P.D.C. was supported by a Postdoctoral Fellowship from NSERC Canada. The authors would like to thank Dr. H.C. Fibiger and Eli Lilly for generously donating the LY293558.

\section{REFERENCES}

Arroyo M, Markou A, Robbins TW, Everitt BJ (1998): Acquisition, maintenance and reinstatement of intravenous cocaine self-administration under a second-order schedule of reinforcement in rats: effects of conditioned cues and continuous access to cocaine. Psychopharmacol (Berl) 140:331-344

Barrot M, Marinelli M, Abrous DN, Rouge-Pont F, Le Moal M, Piazza PV (1999): Functional heterogeneity in dopamine release and in the expression of fos-like proteins within the rat striatal complex [In Process Citation]. Eur J Neurosci 11:1155-1166

Berridge KC, Robinson TE (1998): What is the role of dopamine in reward: hedonic impact, reward learning, or incentive salience? Brain Res Rev 28:309-369

Blaha CD, Yang CR, Floresco SB, Barr AM, Phillips AG (1997): Stimulation of the ventral subiculum of the hippocampus evokes glutamate receptor-mediated changes in dopamine efflux in the rat nuclaus accumbens. Eur J Neurosci 9:902-911

Bleakman R, Schoepp DD, Ballyk B, Bufton H, Sharpe EF, Thomas K, Ornstein PL, Kamboj RK (1996): Pharmacological discrimination of GluR5 and GluR6 kainate receptor subtypes by $(3 \mathrm{~S}, 4 \mathrm{aR}, 6 \mathrm{R}, 8 \mathrm{aR})-6-[2-(1(2) \mathrm{H}$-tetrazole-5-yl)ethyl]decahyd roisdoquinoline-3 carboxylicacid. Mol Pharmacol 49:581-585 
Boldry RC, Layer RT, Wallace LJ, Uretsky NJ (1992): Stimulation of locomotor activity by intra-accumbens AMPA is not inhibited by neonatal 6-hydroxydopamineinduced lesions. Neurosci Lett 138:265-269

Burns LH, Everitt BJ, Kelley AE, Robbins TW (1994): Glutamate-dopamine interactions in the ventral striatum: role in locomotor activity and responding with conditioned reinforcement. Psychopharmacol 115:516-528

Burns LH, Robbins TW, Everitt BJ (1993): Differential effects of excitotoxic lesions of the basolateral amygdala, ventral subiculum and medial prefrontal cortex on responding with conditioned reinforcement and locomotor activity potentiated by intra-accumbens infusions of $d$-amphetamine. Behav Brain Res 55:167-183

Bussey TJ, Everitt BJ, Robbins TW (1997): Dissociable effects of cingulate and medial frontal cortex lesions on stimulus-reward learning using a novel Pavlovian autoshaping procedure for the rat: implications for the neurobiology of emotion. Behav Neurosci 111:908-919

Cador M, Robbins TW, Everitt BJ (1989): Involvement of the amygdala in stimulus-reward associations: Interaction with the ventral striatum. Neurosci 30:77-86

Caine SB, Lintz R, Koob GF (1992): Intravenous self-administration techniques in animals. In Sahgal A (ed), Behavioral Neuroscience: a practical approach. Oxford, Oxford University Press, pp 117-143

Cardinal R (2000): Whisker, Version 1.0, computer software. URL: http:/ / www.pobox.com/users/rudolf/whisker

Cervo L, Samanin R (1995): Effects of dopaminergic and glutamatergic receptor antagonists on the acquisition and expression of cocaine conditioning place preference. Brain Res 673:242-250

Cervo L, Samanin R (1996): Effects of dopaminergic and glutamatergic receptor antagonists on the establishment and expression of conditioned locomotion to cocaine in rats. Brain Res 731:31-38

Childress AR, Mozley PD, McElgin W, Fitzgerald J, Reivich M, O'Brien CP (1999): Limbic activation during cueinduced cocaine craving. Am J Psychiatry 156:11-18

Cornish JL, Duffy P, Kalivas PW (1999): A role for nucleus accumbens glutamate transmission in the relapse to cocaine-seeking behavior. Neurosci 93:1359-1367

Cornish JL, Kalivas PW (2000): Glutamate transmission in the nucleus accumbens mediates relapse in cocaine addiction. J Neurosci 20:RC89 81-85

Di Ciano P, Blaha CD, Phillips AG (1998a): Conditioned changes in dopamine oxidation currents in the nucleus accumbens of rats by stimuli paired with self-administration or yoked administration of $d$-amphetamine. Eur J Neurosci 10:1121-1127

Di Ciano P, Blaha CD, Phillips AG (1998b): The relation between dopamine oxidation currents in the nucleus accumbens and conditioned increases in motor activity in rats following repeated administration of $d$-amphetamine or cocaine. Eur J Neurosci 10:1113-1120

Druhan, JP, Wilent, WB (1999): Effects of the competitive $\mathrm{N}$-methyl-D-aspartate receptor antagonist, CPP, on the development and expression of conditioned hyperactivity and sensitization induced by cocaine. Behav Brain Res 102:195-210
Everitt BJ, Parkinson JA, Olmstead MC, Arroyo M, Robledo P, Robbins TW (1999): Associative processes in addiction and reward. The role of amygdala- ventral striatal subsystems. Ann N Y Acad Sci 877:412-438

Everitt BJ, Robbins TW (2000): Second-order schedules of drug reinforcement: measurement of reinforcing efficacy and drug-seeking behaviour. Psychopharmacol 153:17-30

Floresco SB, Yang CR, Phillips AG, Blaha CD (1998): Basolateral amygdala stimulation evokes glutamate receptordependent dopamine efflux in the nucleus accumbens of the anaesthetized rat. Eur J Neurosci 10:1241-1251

Fray PJ, Sahakian BJ, Robbins TW, Koob GF, Iversen SD (1980): An observational model for quantifying the behavioural effects of dopamine agonists: Contrasting effecst of $d$-amphetamine and apomorphine. Psychopharmacol 69:253-259

Gawin FH, Kleber HD (1986): Abstinence symptomatology and psychiatric diagnosis in cocaine abusers. Arch Gen Psychiatry 43:107-113

Goldberg SR, Kelleher RT, Morse WH (1975): Second-order schedules of drug injection. Fed Proc 34:1771-1776

Gratton A, Wise RA (1994): Drug- and behavior-associated changes in dopamine-related electrochemical signals during intravenous cocaine self- administration in rats. J Neurosci 14:4130-4146

Grimm JW, See RE (2000): Dissociation of primary and secondary reward-relevant limbic nuclei in an animal model of relapse. Neuropsychopharmacol 22:473-479

Groenewegen HJ, Berendse HW, Meredith GE, Haber SN, Voorn P, Wolters JG, Lohman AHM (1991): Functional anatomy of the ventral, limbic system-innervated striatum. In Willner P, Scheel-Kruger J (eds), The Mesolimbic Dopamine System: From Motivation to Action. New York, John Wiley \& Sons, pp 19-53

Groenewegen HJ, Vermeulen-Van der Zee E, te Kortschot A, Witter MP (1987): Organization of the projections from the subiculum to the ventral striatum in the rat. A study using anterograde transport of Phaseolus vulgaris leucoagglutinin. Neurosci 23:103-120

Groenewegen HJ, Wright CI, Beijer AV, Voorn P (1999): Convergence and segregation of ventral striatal inputs and outputs. Ann N Y Acad Sci 877:49-63

Groenewegen HJ, Wright CI, Beijer AVJ (1996): The nucleus accumbens: gateway for limbic structures to reach the motor system. In Holstege G, Bandler R, Saper CB (eds), Progress in Brain Research, Vol 107: Amsterdam, Elsevier pp 485-511

Hauber W, Bohn I, Giertler C (2000): NMDA, but not dopamine $\mathrm{D}(2)$, receptors in the rat nucleus accumbens are involved in guidance of instrumental behavior by stimuli predicting reward magnitude. J Neurosci 20:6282-6288

Heimer L, Zahm DS, Churchill L, Kalivas PW, Wohltmann C (1991): Specificity in the projection patterns of accumbal core and shell in the rat. Neurosci 41:89-125

Ito R, Dalley JW, Howes SR, Robbins TW, Everitt BJ (2000): Dissociation in conditioned dopamine release in the nucleus accumbens core and shell in response to cocaine cues and during cocaine-seeking behaviour in rats. J Neurosci 20:7489-7495 
Jackson A, Mead AN, Rocha BA, Stephens DN (1998): AMPA receptors and motivation for drug: effect of the selective antagonist NBQX on behavioural sensitization and on self-administration in mice. Behav Pharmacol 9:457-467

Kaddis FG, Uretsky NJ, Wallace LJ (1995): DNQX in the nucleus accumbens inhibits cocaine-induced conditioned place preference. Brain Res 697:76-82

Kelley AE, Smith-Roe SL, Holahan MR (1997): Responsereinforcement learning is dependent on N-methylD-aspartate receptor activation in the nucleus accumbens core. Proc Natl Acad Sci USA 94:12174-12179

Kelley AE, Domesick VB, Nauta JH (1982): The amygdalostriatal projectionin the rat- an anatomical study by anterograde and retrograde tracing methods. Neurosci 7:615-630

Kiyatkin E, Stein E (1996): Conditioned changes in nucleus accumbens dopamine signal established by intravenous cocaine in rats. J Neurochem 211:73-76

Koob GF (1999): The role of the striatopallidal and extended amygdala systems in drug addiction. Ann N Y Acad Sci 877:445-460

Li Y, Vartanian AJ, White FJ, Xue CJ, Wolf ME (1997): Effects of the AMPA receptor antagonist NBQX on the development and expression of behavioral sensitization to cocaine and amphetamine. Psychopharmacol (Berl) 134:266-276

Lovibond PF (1983): Facilitation of instrumental behavior by a Pavlovian appetitive conditioned stimulus. J Exp Psychol Anim Behav Process 9:225-247

Maldonaldo-Irizarry CS, Kelley AE (1994): Differential behavioral effects following microinjection of an NMDA antagonist into nucleus accumbens subregions. Psychopharmacol 116:65-72

Martin-Iversen MT, Szostak C, Fibiger HC (1986): 6-Hydroxydopamine lesions of the medial prefrontal cortex fail to influence intravenous self-administration of cocaine. Psychopharmacol 88:310-314

Mead AN, Stephens DN (1998): AMPA-receptors are involved in the expression of amphetamine-induced behavioural sensitisation, but not in the expression of amphetamine-induced conditioned activity in mice. Neuropharmacology 37:1131-1138

Meil WM, See RE (1997): Lesions of the basolateral amygdala abolish the ability of drug associated cues to reinstate responding during withdrawal from selfadministered cocaine. Behav Brain Res 87:139-148

O'Brien CP, Childress AR, Ehrman R, Robbins SJ (1998): Conditioning factors in drug abuse: can they explain compulsion? J Psychopharmacol 12:15-22

Pap A, Bradberry CW (1995): Excitatory amino acid antagonists attenuate the effects of cocaine on extracellular dopamine in the nucleus accumbens. J Pharmacol Exp Ther 274:127-133

Parkinson JA, Olmstead MC, Burns LH, Robbins TW, Everitt BJ (1999): Dissociation in effects of lesions of the nucleus accumbens core and shell on appetitive pavlovian approach behavior and the potentiation of conditioned reinforcement and locomotor activity by D-amphetamine. J Neurosci 19:2401-2411
Parkinson JA, Robbins TW, Everitt BJ (2000a): Dissociable roles of the central and basolateral amygdala in appetitive emotional learning. Eur J Neurosci 12:405-413

Parkinson JA, Willoughby PJ, Robbins TW, Everitt BJ (2000b): Disconnection of the anterior cingulate cortex and nucleus accumbens core impairs Pavlovian approach behavior: further evidence for limbic corticalventral striatopallidal systems [In Process Citation]. Behav Neurosci 114:42-63

Paxinos G, Watson C (1986): The Rat Brain in Stereotaxic Coordinates. Sydney, Australia, Academic Press

Pierce R, Kalivas PW (1995): Amphetamine produces sensitized increases in locomotion and extracellular dopamine preferentially in the nucleus accumbens shell of rats administered repeated cocaine. J Pharmacol Exp Ther 275:1019-1029

Pilla M, Perachon S, Sautel F, Garrido F, Mann A, Wermuth CG, Schwartz JC, Everitt BJ, Sokoloff P (1999): Selective inhibition of cocaine-seeking behaviour by a partial dopamine D3 receptor agonist [In Process Citation]. Nature 400:371-375

Pontieri FE, Tanda G, Di Chiara G (1995): Intravenous cocaine, morphine, and amphetamine preferentially increase extracellular dopamine in the "shell" as compared with the "core" of the rat nucleus accumbens. Proc Natl Acad Sci U S A 92:12304-12308

Pulvirenti L, Berrier R, Kreifeldt M, Koob GF (1994): Modulation of locomotor activity by NMDA receptors in the nucleus accumbens core and shell regions of the rat. Brain Res 664:231-236

Pulvirenti L, Maldonado-Lopez R, Koob GF (1992): NMDA receptors in the nucleus accumbens modulate intravenous cocaine but not heroin self-administration in the rat. Brain Res 594:327-330

Roberts DCS, Koob GF (1982): Disruption of cocaine selfadministration following 6- hydroxydopamine lesions of the ventral tegmental area in rats. Pharmacol Biochem Behav 17:901-904

Roberts DCS, Koob GF, Klonoff P, Fibiger HC (1980): Extinction and recovery of cocaine self-administration following 6-hydroxydopamine lesions of the nucleus accumbens. Pharmacol Biochem Behav 12:781-787

Robinson TE, Berridge KC (1993): The neural basis of drug craving: an incentive-sensitization theory of addiction. Brain Res Rev 18:247-291

Roozendaal B, Oldenburger WP, Strubbe JH, Koolhaas JM, Bohus B (1990): The central amygdala is involved in the conditioned but not the meal-induced cephalic insulin response in the rat. Neurosci Lett 116:210-215

Schoepp DD, Lodge D, Bleakman D, Leander JD, Tizzano JP, Wright RA, Palmer AJ, Salhoff CR, Ornstein PL (1995): In vitro and in vivo antagonism of AMPA receptor activation by (3S, 4aR, 6R, 8aR)-6-[2-(1(2)H-tetrazole-5-yl) ethyl] decahydroisoquinoline- 3-carboxylic acid. Neuropharmacology 34:1159-1168

Stephens DN, Brown G (1999): Disruption of operant oral self-administration of ethanol, sucrose, and saccharin by the AMPA/kainate antagonist, NBQX, but not the AMPA antagonist, GYKI 52466. Alcohol Clin Exp Res 23:1914-1920 
Stratford TR, Kelley A (1997): GABA in the nucleus accumbens shell participates in the central regulation of feeding behavior. The Journal of Neuroscience 17:4434-4440

Stratford TR, Swanson CJ, Kelley A (1998): Specific changes in food intake elicitied by blockade or activation of gluatamate receptos in the nucleus accumbens shell. Behav Brain Res 93:43-50

Svensson L, Zhang J, Johannessen K, Engel JA (1994): Effect of local infusion of glutamate analogues into the nucleus accumbens of rats: an electrochemical and behavioural study. Brain Res 643:155-161

Taylor JR, Horger BA (1999): Enhanced responding for conditioned reward produced by intra-accumbens amphetamine is potentiated after cocaine sensitization. Psychopharmacol (Berl) 142:31-40

Taylor JR, Robbins TW (1984): Enhanced behavioural control by conditioned reinforcers following microinjections of d-amphetamine in to the nucleus accumbens. Psychopharmacol 84:405-412

Taylor JR, Robbins TW (1986): 6-Hydroxydopamine lesions of the nucleus accumbens, but not of the caudate nucleus, attenuate enhanced responding with reward- related stimuli produced by intra-accumbens $d$-amphetamine. Psychopharmacol 90:390-397

Walaas I, Fonnum F (1980): Biochemical evidence for glutamate as a transmitter in hipocampal efferents to the basal forebrain and hypothalamus in the rat. Neurosci 5:1691-1698

Whitelaw RB, Markou A, Robbins TW, Everitt BJ (1996): Excitotoxic lesions of the basolateral amygdala impair the acquisition of cocaine-seeking behaviour under a second-order schedule of reinforcement. Psychopharmacol 127:213-224

Wise RA (1996): Neurobiology of addiction. Curr Opin Neurobiol 6:243-251

Wu M, Brudzynski SM, Mogenson GJ (1993): Functional interaction of dopamine and glutamate in the nucleus accumbens in the regulation of locomotion. Can J Physiol Pharmacol 71:407-413

Wyvell CL and Berridge KC (2000): Intra-accumbens amphetamine increases the conditioned incentive salience of sucrose reward: enhancement of reward "wanting" without enhanced "liking" or response reinforcement. J Neurosci 20:8122-8130 